\title{
Multiple Restricted Origin of Oligodendrocytes
}

\author{
N. Spassky, ${ }^{1}$ C. Goujet-Zalc, ${ }^{1}$ E. Parmantier, ${ }^{1}$ C. Olivier, ${ }^{1}$ S. Martinez, ${ }^{2}$ A. Ivanova, ${ }^{3}$ K. Ikenaka, ${ }^{3}$ W. Macklin, ${ }^{4}$ \\ I. Cerruti, ${ }^{5}$ B. Zalc, ${ }^{1}$ and J.-L. Thomas ${ }^{1}$
}

${ }^{1}$ Biologie des Interactions Neurones/Glie, Institut National de la Santé et de la Recherche Médicale U-495, Université Pierre Marie Curie, Hôpital de la Salpêtrière, 75651 Paris Cedex 13, France, 2Departemento de Ciencas et Morfologicas, Universitad de Murcia and Instituto de Neurociencias, Universidad de Alicante, 30071 Murcia, Spain, ${ }^{3 N a t i o n a l ~ I n s t i t u t e ~}$ for Physiological Sciences, Okazaki National Research Institutes, Okazaki, Aichi 444, Japan, ${ }^{4}$ Cleveland Clinic Foundation, Department of Neurosciences NC-30, Cleveland, Ohio 44106, and '5Service d'Experimentation Animale et de Transgenèse, Centre National de la Recherche Scientifique, 94801 Villejuif, France

The plp gene encodes the proteolipid protein and its alternatively spliced product DM-20, major proteins of CNS myelin. In the mouse, $p / p / d m-20$ transcripts are expressed beginning at embryonic day 9.5 (E9.5) by restricted foci of germinative neuroepithelial cells. To determine the identity of the neural precursors expressing $p / p / d m-20$, a zeomycin resistance gene fused to the lac $Z$ reporter was expressed in transgenic mice under the control of the plp regulatory sequences. In the three different lines generated, the pattern of $\beta$-galactosidase expression was similar and superimposable on the expression pattern of endogenous $p / p / d m-20$. Both in vivo and in vitro, the transgene was expressed by $\mathrm{O}_{4}^{+}$pre-oligodendrocytes, and later by $\mathrm{RIP}^{+}$differentiated oligodendrocytes, but not by neuronal cells, astrocytes, or radial glial cells. After zeomycin selection, a dramatic enrichment in $\mathrm{O}^{+}$pre-oligodendrocytes was observed in cultures derived from E12.5 transgenic embryos. This enrichment indicates the oligodendroglial specification of neural precursors that continuously express $p / p / d m-20$. Early p/p/dm-20-expressing precursors, however, appear to be a separate population from previously described PDGFR $\alpha$ oligodendrocyte precursors, as shown by the striking differences in their (1) patterns of distribution and (2) responsiveness to PDGF. These data suggest that oligodendrocytes have a plural origin and that early $p / p / d m-20$ defines one of the neural lineages generating oligodendrocytes.

Key words: myelin; neural precursors; oligodendrocyte; oligodendroglial specification; platelet-derived growth factor $\alpha$ receptor; proteolipid protein
Oligodendrocytes are the myelin-forming cells in the CNS. A series of observations suggest that commitment to the oligodendrocyte lineage occurs in specific regions of the neural tube. These "precursor" cells, located in the germinative neuroepithelium, give rise to "progenitors" that migrate to their correct location, where they differentiate into oligodendrocytes. For example, before embryonic day 16 (E16), cultures of the rat optic stalk do not give rise to oligodendrocytes, which suggests that the progenitors observed after E16 were generated elsewhere in the brain and had invaded the optic stalk (Small et al., 1987). It has been shown that oligodendrocytes in the chick optic nerve originate from a focal ventral region of the third ventricle (Ono et al., 1997). In the rat, before E14, only the ventral portion, but not the

Received June 8, 1998; revised July 30, 1998; accepted Aug. 7, 1998.

N.S. and C.O. are fellows of Ministère de l'Enseignement Supérieur et de la Recherche. This study was supported by Institut National de la Santé et de la Recherche Médicale (INSERM) and by grants from the Council for Tobacco Research (No. 3952), European Leucodystrophy Association, and Association de Recherche sur la Sclérose En Plaques to B.Z., by European Commission Contract BMH4-CT96-0249 to S.M. and B.Z., by Fundation la Caixa (Grant 97/101-00) to S.M., and by INSERM/Japanese Society for the Promotion of Science to K.I. and B.Z. We are greatly indebted to the following colleagues for the gifts of valuable reagents: A. Frankfurter for TuJ1 antibody, Dr. C. Goridis for anti-Phox-2b antiserum, Dr. F. Guillemot for NeuroD cDNA, Dr. P. LePrince for RC2 antibody, Dr. J. Levine for anti-NG2 antiserum, and Dr. W. Richardson for PDGFR $\alpha$ cDNA. We thank Drs. H. Baba, C. Goridis, C. Henderson, C. Klämbt, S. Leather, M. Ruberg, S. Taite, and M.-A. Teillet for careful reading and helpful criticism of this manuscript.

N.S. and C.G.-Z. contributed equally to this paper.

Correspondence should be addressed to B. Zalc, Biologie des Interactions Neurones/Glie, Institut National de la Santé et de la Recherche Médicale U-495 Hôpital de la Salpêtrière, 75651 Paris Cedex 13, France.

Copyright (ㄷ) 1998 Society for Neuroscience $\quad 0270-6474 / 98 / 188331-13 \$ 05.00 / 0$ dorsal half of the thoracolumbar spinal cord, can give rise to oligodendrocytes (Wharf et al., 1991; Noll and Miller, 1993; Miller, 1996).

It has been suggested that oligodendrocyte precursors can be distinguished from other neuroepithelial cells by their expression of platelet-derived growth factor $\alpha$-receptors (PDGFR $\alpha)$ transcripts (Pringle and Richardson, 1993). In the rat spinal cord, at E14, the PDGFR $\alpha^{+}$cells are localized in the ventral half, where they form two longitudinal columns on either side of the central canal. When PDGFR $\alpha^{+}$cells are purified from embryonic rat spinal cord by immunoselection, they differentiate into oligodendrocytes (Hall et al., 1996).

A second possible marker is $d m-20$ mRNA, an alternative spliced product of the plp (proteolipid protein) gene (Timsit et al., 1995). PLP and DM-20 are the most abundant proteins of CNS myelin (Lees and Brostoff, 1984). Although PLP is expressed during the final stages of oligodendrocyte maturation, the corresponding transcripts are detected much earlier during development (Kanfer et al., 1989; Lubetzki et al., 1991). During mouse embryonic development, both the $d m-20$ and trace amounts of $p l p$ transcripts have been detected by RT-PCR (Ikenaka et al., 1992; Timsit et al., 1992; Dickinson et al., 1996). Using in situ hybridization, we detected plp/dm-20 in the CNS, beginning at E9.5. Expression of these transcripts was restricted to subsets of neuroepithelial cells in the laterobasal plate of the diencephalon, the caudal hypothalamus, the rhombencephalon, and the spinal cord (Timsit et al., 1995). Between the time of emergence and birth, the number of $p l p / d m-20^{+}$cells increased, and they progressively 
invaded the future white matter tracts, as expected of cells belonging to the oligodendrocyte lineage (Timsit et al., 1995). Although $p l p / d m-20^{+}$and PDGFR $\alpha^{+}$cells were both located in the ventral and lateroventral spinal cord, the two messages did not appear to be coexpressed by the same cells (Yu et al., 1994). This discrepancy led $\mathrm{Yu}$ et al. (1994) to question the identity of plp/dm-20 ${ }^{+}$ventricular cells as oligodendrocyte precursors.

To pursue this question further, we have generated a transgenic mouse expressing a gene conferring resistance to zeomycin fused to the lacZ reporter under the control of $p l p$ regulatory sequences. Using this tool, we provide direct evidence that cells continuously expressing $\mathrm{plp} / \mathrm{dm}$-20 in the germinative neuroepithelium are neural precursors that give rise to oligodendrocytes. We also show a lack of coincidence of $p l p / d m-20$ - and PDGFR $\alpha$ expressing precursors. We therefore propose that these two separate populations of neuroectodermal cells could represent distinct oligodendroglial lineages.

\section{MATERIALS AND METHODS}

Transgene construction and transgenic mice production. Plasmid pUT 111 containing the sh ble-lac $Z$ fusion gene and SV40 polyadenylation signal sequence was obtained from Cayla (Toulouse, France). The NcoI restriction site of pUT111 was converted to a $S p h$ I site by removal of the 5 '-overhang with T4 DNA polymerase and the subsequent ligation of a SphI synthetic linker (5'-GGCATGCC-3'; Genset, Paris, France). The final construct was designated plp-sh ble-lacZ and was generated by replacing the sh ble-lacZ expression cassette (SphI-NotI fragment of pUT111) in PLP (+Z) plasmid (Wight et al., 1993). The plp-sh ble-lacZ plasmid was digested with $A p a \mathrm{I}$ and $N o t \mathrm{I}$ and fractionated on a $0.7 \%$ agarose gel. A $15 \mathrm{~kb}$ band of DNA was excised from the gel and purified on a Prep-A-Gene DNA matrix (Bio-Rad, Ivry, France). DNA was microinjected into the male pronucleus of fertilized eggs derived from $\left(\mathrm{C} 57 \mathrm{bl} / 6 \mathrm{xDBA}_{2}\right) \mathrm{F} 1$ females mated to identical hybrid males. Eggs surviving micromanipulation were transferred to the oviducts of pseudopregnant foster mothers according to described methods (Hogan et al., 1986). Founder mice were identified by PCR analysis of DNA prepared from tail biopsies collected at weaning, using as the $5^{\prime}$ primer zeo1 (5'-CCAAGTTGACCAGTGCCGTT-3') and the $3^{\prime}$ primer zeo2 $\left(5^{\prime}\right.$ TGGACACGACCTCCGACCAC $-3^{\prime}$ ), which are complementary to the sh ble sequence. Positivity of DNA samples for sh ble was confirmed by PCR analysis using as the $5^{\prime}$ primer lacZ1 (5'-GTCGTTTT ACAACGTCGTGACT3') and the $3^{\prime}$ primer lacZ2 (5'-GATGGGCGC ATCGTAACCGTGC-3'), which are complementary to the lac $Z$ sequence. The animals used in this study were obtained by crossing homozygous transgenic males with OF1 females and thus were heterozygous. OF1 is an outbred nontransgenic line (IFFA-CREDO, L'Arbresle, France). The average gestation period lasts $19.5 \mathrm{~d}$. The midpoint of the dark interval during which mating occurred was designated as day 0 , and the embryos were considered to be E0.5 on the morning after fertilization.

Antibodies. Mouse monoclonal A2B5 antibody (IgM) is a hybridoma supernatant (Eisenbarth et al., 1979) (ATCC) that was used at a 1:1 dilution. Mouse monoclonal O4 antibody (IgM), also a hybridoma supernatant (Sommer and Schachner, 1981), was diluted 1:5 in either 10\% normal goat serum (NGS), $1 \%$ gelatin, $5 \%$ BSA, and $0.05 \%$ sodium azide in PBS (Warrington and Pfeiffer, 1992; Hardy and Friedrich, 1996) or in $10 \%$ fetal calf serum (FCS) (Eurobio, Les Ulis, France) in DMEM for immunostaining on vibratome sections or cell cultures, respectively. The $\mathrm{RC} 2$ monoclonal antibody $(\mathrm{mAb})$ was a gift of $\mathrm{P}$. Leprince (Liège, Belgium) and was used diluted 1:30. The anti-NG2 chondroitin-sulfate proteoglycan rabbit antiserum, a generous gift of J. Levine (State University of New York, Stony Brook, NY) (Levine and Stallcup, 1987) was diluted 1:600. The anti- $\beta$-galactosidase rabbit polyclonal antibody (Organon, Technika, West Chester, PA) was diluted 1:500, and the mouse monoclonal antibody (JIE7 hybridoma supernatant; DSHB) was diluted 1:2. The anti-Hu polyclonal antibody (a gift of J.-Y. Delattre, Hopital de la Salpêtrière, Paris) was obtained from a patient with a paraneoplastic syndrome and diluted 1:10,000. The anti-Phox $2 \mathrm{~b}$ rabbit polyclonal antibody was a gift of C. Goridis (Luminy, France) and was diluted 1:1000 in $0.05 \%$ Triton X-100 and 5\% FCS in PBS. The mouse monoclonal TuJ1 antibody (IgG2a) (Easter et al., 1993) was a gift of A. Frankfurter
(University of Virginia, Charlottesville, VA) and was diluted 1:1000. For immunostaining on cryosections, $\mathrm{TuJ} 1$ was diluted in $0.2 \%$ gelatin, $0.2 \%$ Triton X-100, $0.1 \mathrm{~m}$ lysine, and $0.1 \%$ sodium azide in PBS. The anti-cow glial fibrillary acidic protein (GFAP), rabbit polyclonal antibody was purchased from Dakopatts (Glostrup, Denmark), and was diluted 1:200. Mouse monoclonal RIP antibody (IgG1), a culture supernatant, was a gift of Dr. B. Friedman (Regeneron) (Friedman et al., 1989) and was diluted 1:2. Fluorescein and rhodamine-conjugated goat antibodies against mouse IgM, fluorescein, coumarin, and rhodamine-conjugated goat antibodies against rabbit IgG, and rhodamine-conjugated goat antibodies against mouse IgG2a or IgG1 were from Southern Biotechnology (Birmingham, AL) and were diluted 1:100. Biotin-conjugated goat antibody against mouse $\operatorname{IgG}$ and mouse monoclonal antibody against bromodeoxyuridine (BrdU) (all from Amersham, Arlington Heights, IL) were diluted 1:200. Vectastain Elite ABC reagent (Vector Laboratories, Burlingame, CA) was diluted 1:200. Unless specified otherwise, all antibodies were diluted in PBS containing $0.2 \%$ gelatin and $0.2 \%$ Triton $\mathrm{X}-100$.

Detection of $\beta$-galactosidase enzymatic activity. Brains and spinal cord were dissected in $0.1 \mathrm{M}$ PBS, $\mathrm{pH} 7.4$, fixed by immersion in $2 \%$ paraformaldehyde (PFA) for $10 \mathrm{~min}$ on ice, washed twice in PBS, and stained for $6-15 \mathrm{hr}$ at $37^{\circ} \mathrm{C}$. The staining solution contained $2 \mathrm{~mm} 5$-bromo-4-chloro3 -indolyl- $\beta$-Dgalactoside (X-gal) (United States Biochemical, Cleveland, $\mathrm{OH}$ ), or 5-bromo-3-indolyl- $\beta$-D-galactoside (Bluo-gal; Life TechnologiesBRL, Gaithersburg, MD), $20 \mathrm{~mm}$ potassium ferrocyanide, $20 \mathrm{~mm}$ potassium ferricyanide, and $2 \mathrm{mM} \mathrm{MgCl}_{2}$ in PBS. The stained embryos were rinsed twice in PBS, post-fixed overnight in $4 \%$ PFA at $4^{\circ} \mathrm{C}$, and clarified either in glycerol (diluted 1:1 in PBS) or in a benzyl-benzoate/benzyl alcohol solution 2:1 (Levi et al., 1996).

Tissue preparation for immunohistochemistry. X-gal-stained or unstained embryos were fixed by overnight immersion at $4^{\circ} \mathrm{C}$ in $4 \%$ PFA in $0.1 \mathrm{M}$ PBS. Newborn transgenic mice were killed by perfusion through the left ventricle and post-fixed overnight with $4 \%$ PFA. Embryos were then rinsed in PBS, cryoprotected in PBS containing 15\% sucrose for 12 $\mathrm{hr}$ at $4^{\circ} \mathrm{C}$, embedded in $15 \%$ sucrose and $7.5 \%$ gelatin in PBS, frozen in melting isopentane, and cut on a Microm cryostat in $20 \mu \mathrm{m}$ sections. Alternatively, the embryos were embedded in low melting point agarose and cut on a vibratome in $90-\mu \mathrm{m}$-thick sections. For indirect immunofluorescence labeling, before incubation with antibodies, vibratome sections were blocked for $1 \mathrm{hr}$ in $10 \% \mathrm{NGS}, 1 \%$ gelatin, $5 \% \mathrm{BSA}$, and $0.05 \%$ sodium azide in PBS (Warrington and Pfeiffer, 1992; Hardy and Friedrich, 1996). Cryosections were blocked in 50\% sheep serum and $10 \%$ fetal calf serum in DMEM or in PBS containing $0.2 \%$ gelatin, $0.2 \%$ Triton X-100, $0.1 \mathrm{M}$ lysine, and $0.1 \%$ sodium azide. Sections were incubated with primary antibodies overnight at $4^{\circ} \mathrm{C}$, rinsed in PBS, and then incubated with fluorochrome-conjugated secondary antibodies for either 1 or $3 \mathrm{hr}$ at room temperature, followed by three washes in PBS (20 min each). Sections were then mounted in Fluoromount (Clinisciences, Paris, France) to prevent fading of fluorescence.

For immunoperoxidase staining, endogenous peroxidase was inhibited by immersion of sections in $0.2 \%$ Triton X-100 and $1.5 \% \mathrm{H}_{2} \mathrm{O}_{2}$ in PBS for $15 \mathrm{~min}$ at room temperature. After they were blocked, the sections were incubated with the first antibody at $4^{\circ} \mathrm{C}$ overnight. The next day, after excess antibody was rinsed off, sections were incubated with the biotinconjugated secondary antibody for $1 \mathrm{hr}$ at room temperature and then with the Vectastain-Elite-ABC reagent. After two washes (10 min each) in $0.1 \mathrm{M}$ Tris-HCl, $\mathrm{pH} 7.6$, peroxidase activity was revealed using 3.3'diaminobenzidine tetrahydrochloride (Dakopatts) as a chromogen at a concentration of $1 \mathrm{mg} / \mathrm{ml}$ in $0.1 \mathrm{M}$ Tris-HCl, $\mathrm{pH}$ 7.6. All steps were followed by three $20 \mathrm{~min}$ washes in PBS. Sections were dehydrated in graded ethanol, transferred to xylene, and then mounted with Eukitt (Prolabo, Paris, France). Immunolabeled sections were examined and photographed under a Leica DRMB microscope.

In situ hybridization. Patterns of gene transcription were determined by in situ hybridization (ISH) using digoxigenin (DIG)-labeled cRNA antisense probes (Boehringer Mannheim, Mannheim, Germany) transcribed from mouse plp/dm-20 (Timsit et al., 1992), PDGFR $\alpha$ (Pringle and Richardson, 1993) and neuroD (gift from F. Guillemot, Illkirch, France) cDNAs cloned into pBluescriptKS-. Whole-mount hybridization was performed as described by Henrique et al. (1995). ISH on cryostat sections was performed according to the protocol of Strähle et al. (1994) modified by Myat et al. (1996). For whole-mount double-labeling with $\beta$-gal and in situ hybridization, $\beta$-gal activity was detected before in situ hybridization, as described above. Embryos were then washed $3 \times 15 \mathrm{~min}$ in PBS containing $0.1 \%$ Tween-20 (PBT) and refixed overnight in $4 \%$ 
PFA before being processed for ISH. For double ISH, cRNA probes synthesized with either DIG-UTP or fluorescein-UTP (Boehringer Mannheim) were detected with alkaline phosphatase (AP)-conjugated anti-DIG or anti-fluorescein antibodies, respectively. The substrate for AP was either 5-bromo-4-chloro-3-indoyl phosphate/nitroblue tetrazolium chloride (BCIP/NBT) (blue) or BCIP/2-[4-iodophenyl]-3-[4nitrophenyl]-5-phenyl tetrazolium chloride (INT) (orange) (Boehringer Mannheim). The more abundant of the two transcripts was detected first. Then the precipitate was fixed with $4 \%$ paraformaldehyde, and AP was inactivated by incubating the sections $(2 \times 5 \mathrm{~min})$ in glycine, $\mathrm{pH}$ 2.2. The cryosections were blocked, and the second AP reaction was performed.

Primary cultures of neuroepithelial cells. Telencephalon, ventral and dorsal diencephalon, mesencephalon, rhombomeres 1 and 2, rhombomeres 3-5, and dorsal and ventral halves of the cervical and thoracolumbar spinal cord were carefully dissected from E12.5 transgenic embryos. After the meninges were removed, cells were first treated with $0.01 \%$ trypsin (Seromed, Noisy Le Grand, France) diluted in Earle's balanced salt solution without calcium or magnesium (EBSS; Life Technologies-BRL) and incubated at $37^{\circ} \mathrm{C}$ in $5 \% \mathrm{CO}_{2}$ for $5 \mathrm{~min}$. Excess trypsin was diluted out in EBSS containing 10\% FCS and then fresh EBSS before the tissue was dissociated by gentle trituration with a Pasteur pipette. After washing, the cell suspension was pelleted and resuspended in DMEM containing 10\% FCS and 0.028\% BSA (Miles, Elkhart, IN). Approximately $5.10^{4}$ cells were plated on poly-L-lysinecoated (Sigma, St. Louis, MO) 14-mm-diameter glass coverslips deposited on the bottom of a 24-well plate (Costar, Cambridge, MA). Cultures were maintained in Bottenstein and Sato (BS) medium (Bottenstein and Sato, 1979) supplemented with $1 \%$ FCS, $1 \%$ penicillin-streptomycin (Seromed, Berlin, Germany), and $10 \mathrm{ng} / \mathrm{ml}$ recombinant platelet-derived growth factor AA (Upstate Biotechnology, Lake Placid, NY).

Immunolabeling of cells in culture. Cultures were fixed for $5 \mathrm{~min}$ in paraformaldehyde $2 \%$ in $0.1 \mathrm{M}$ phosphate buffer, $\mathrm{pH} 7.4$, at room temperature. Where appropriate, cells were stained for X-gal, as above, for $4 \mathrm{hr}$ at $37^{\circ} \mathrm{C}$. After washing and a $10 \mathrm{~min}$ post-fixation in $4 \%$ PFA at room temperature, cells were preincubated for $30 \mathrm{~min}$ in normal sheep serum diluted 1:1 in DMEM/10\% FCS at room temperature. Cells were then incubated for $30 \mathrm{~min}$ with primary antibodies. Excess antibodies were washed out, and cultures were incubated for $30 \mathrm{~min}$ with appropriate fluorochrome-conjugated secondary antibodies. After washing, the nuclei were stained with bis-benzimide solution (Sigma, La Verpilliere, France), and coverslipped with Fluoromount.

Zeomycin treatment. Rostral (mesencephalon and ventral diencephalon) and caudal (rhombencephalon and cervical spinal cord) regions were carefully dissected from E12.5 transgenic embryos. Control cultures were maintained in BS medium to obtain permanent 2 d-conditioned medium (CM). Zeomycin (Zeocin; Cayla, Toulouse, France) was used at the final concentration of $75 \mu \mathrm{g} / \mathrm{ml}$. The first day, and then every other day, culture medium was changed by adding $250 \mu \mathrm{l}$ of CM and $250 \mu \mathrm{l}$ of fresh BS medium containing $150 \mu \mathrm{g} / \mathrm{ml}$ of either zeomycin or BS medium alone.

\section{RESULTS}

\section{Generation of the plp-sh ble-lacZ transgenic mice}

Transgenic mouse lines were generated using the sh ble-lacZ fusion gene driven by the promoter and regulatory sequences of the plp gene, consisting of $2.4 \mathrm{~kb}$ of $5^{\prime}$ flanking plp DNA, all of exon 1 and intron 1 and the first 37 bp of exon 2 (Fig. 1A) (Wight et al., 1993). The sh ble gene, isolated from Streptoalloteichus hindustanus, confers resistance to the antibiotics phleomycin and zeomycin (Gatignol et al., 1988; Drocourt et al., 1990). The addition of the Escherichia coli lacZ gene in frame to the sh ble sequence allows easy detection of transgene-expressing lines. The $15 \mathrm{~kb}$ transgene (ApaI-Not I fragment) was excised from vector sequence and microinjected into the male pronuclei of fertilized eggs recovered from (C57BL/6xDBA2) F1 hybrid females mated to identical hybrid males. DNA extracted from the tails of 34 offspring was analyzed by PCR for the presence of the transgene. Out of seven transgenic founders, one did not survive, two did not transmit the transgene, and one did not express the transgene. The three remaining founder mice had the expected adult pattern of oligodendroglial expression, and lines 1, 14, and 34 were established from these animals. The three plp-sh ble-lac $Z$ lines obtained showed a similar pattern of expression of the transgene, both in the adult and in the embryo (Fig. $1 F-H$ ). A homozygous line was then produced from the selected founder number 34. Its progeny has been analyzed more extensively.

\section{Onset of expression of the transgene}

The $\beta$-gal-expressing cells were first observed at E8.5 in the neural crest of the anterior neural folds (prosencephalic, mesencephalic, and anterior rhombencephalic regions) and the caudal portion of the notocord (Fig. $1 B, C$ ). Cordal expression was transient and could no longer be observed at E9.5, whereas expression in cephalic neural crest cell derivatives persisted throughout development. In the head, mesectodermal cells originating from the neural crest were $\beta$-gal positive $\left(\beta\right.$-gal $\left.{ }^{+}\right)$. In the PNS, the transgene was expressed from E9.5 onward in the condensing cranial ganglia, as well as in the dorsal root and sympathetic and enteric ganglia (Fig. 1D). In neural crest derivatives, endogenous plp and the transgene showed the same timing and pattern of expression (data not shown).

\section{Expression of the transgene in the CNS}

In the CNS, the transgene was first detected at E9.5 in the basal plate of the diencephalon and caudal hypothalamus (Fig. 1D); the $\beta$-gal ${ }^{+}$domain did not include the floor plate, and its medial edge was detected at some distance from the lateral limit of this structure. The correspondence between the patterns of expression of the transgene (Fig. $1 D$ ) and of the endogenous plp/dm-20 gene was verified at this stage by in situ hybridization on sagittal cryosections (Fig. $1 E$ ). At E12.5 (Fig. $1 F-H)$, expression of the transgene extended into the basal plate of the caudal hypothalamus, stopping abruptly at the borders between the mammillary and infundibular region, the limit between prosomers 4 and 5 (Rubenstein et al., 1994). More caudally, basal expression in P2 and P3 extended dorsally into the P2/P3 interprosomeric boundary, i.e., the zona limitans between the ventral and dorsal thalamus. No $\beta$-gal-expressing cells were observed in the midmesencephalic and caudal mesencephalic basal and alar plates. In addition to the ventral territories, $\beta$-gal ${ }^{+}$cells were detected in the dorsal midline at the diencephalomesencephalic junction (Fig. $1 F-H)$, which extended rostrally to cover the pineal region. At E14.5 (Fig. $1 J$ ), most of the $\beta$-gal-expressing cells were observed at a distance from the ventricular zones along the future major white matter tracts such as the diencephalic longitudinal fascicle, the mammillotegmental tract in the basal plate, and the stria medullaris in the alar plate, the $\mathrm{P} 2 / \mathrm{P} 3$ and $\mathrm{P} 3 / \mathrm{P} 4$ intersegmental boundaries. On transversal sections of the CNS from E12.5-14.5 transgenic animals, there was a clear continuum of cells expressing the transgene from the ventricular layer toward the ventrolateral marginal zone like the mammillotegmental tract, or the postoptic commissure in the forebrain, suggesting that the $\mathrm{plp} /$ $d m-20^{+}$precursors are clonally related to the more mature $\mathrm{plp} /$ $d m-20^{+}$progenitors in the tracts (data not shown). At E17.5 and even after birth, some transgene-expressing cells persisted in the ventricular zone in the dorsal midline of the caudal pretectum and rostral tectum, as well as in the dorsal midline of the cerebellum (Fig. $1 K$ ). BrdU incorporation experiments performed just before birth (E18.5-19.5) revealed that transgene-expressing cells in the ventricular zone were replicating their DNA, especially in the lateral, third, and fourth ventricles (data not shown), suggesting that the $p l p / d m-20^{+}$cells in the germinative neuroepithelium are neural precursors. 
A

Apa 1

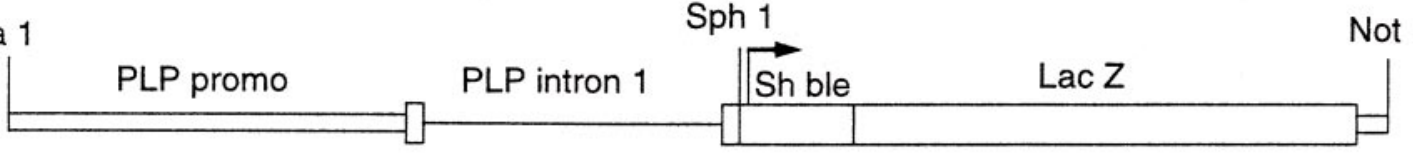

Not 1

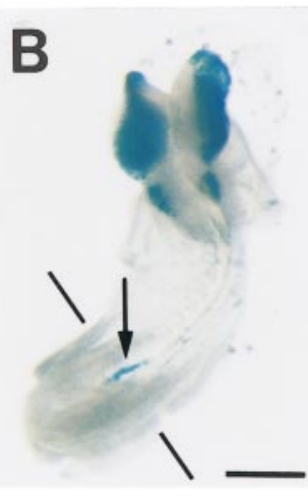

exon 1

exon 2

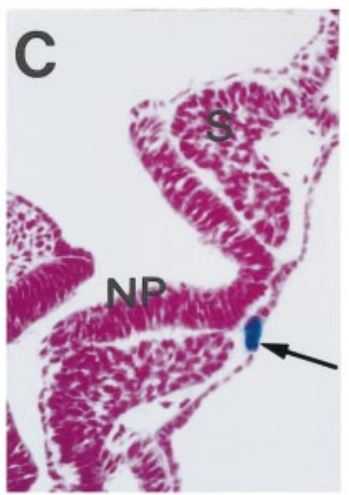

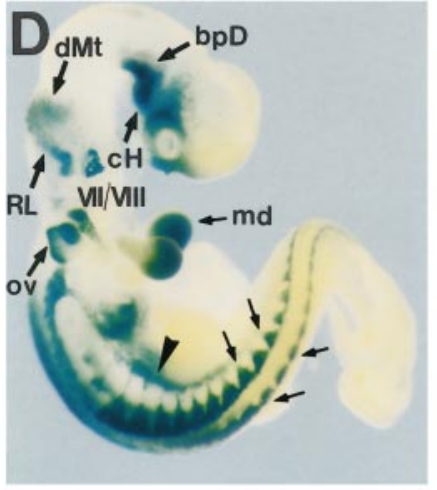

SV40

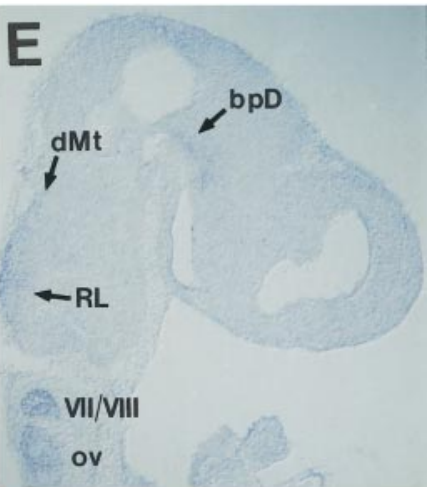

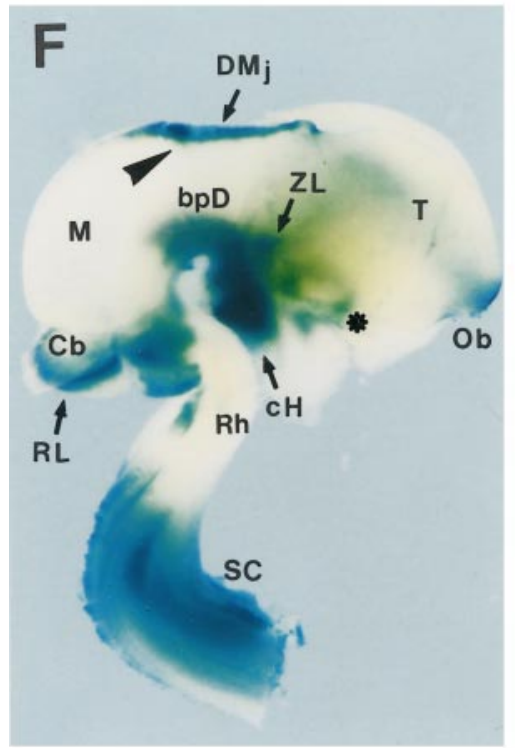
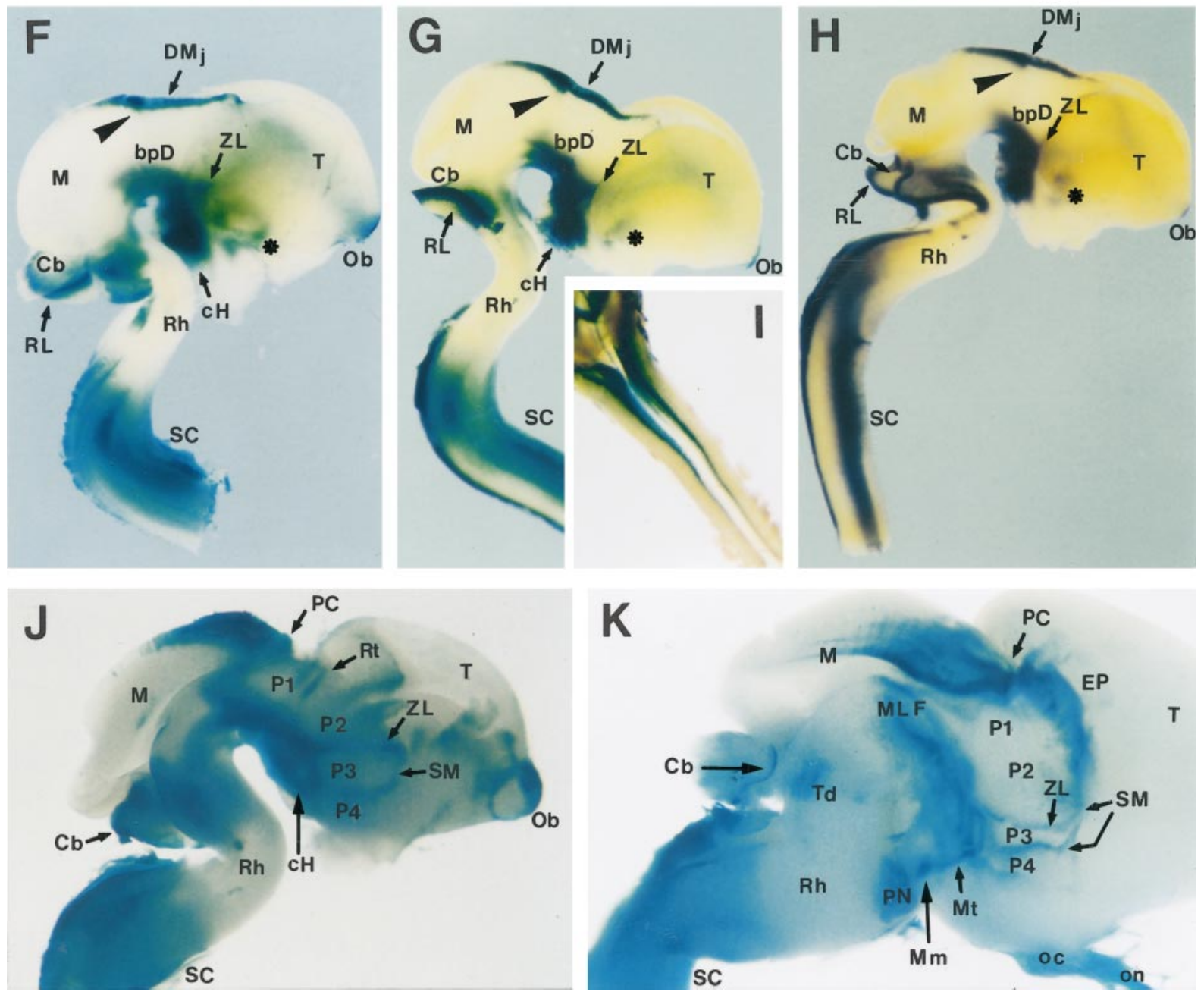

Figure 1. Structure and distribution of the plp-sh ble-lacZ transgene. A, Schematic diagram of the plp-sh ble-lacZ construct. The transgene, consisting of sh ble ( $372 \mathrm{bp})$ fused in frame to the lac $Z$ gene $(3 \mathrm{~kb})$, is under control of the promoter $(2.4 \mathrm{~kb})$, exon 1 , intron 1 ( $8.5 \mathrm{~kb})$, and the first $37 \mathrm{bp}$ of exon 2 of the mouse $p l p$ gene, and the SV40 polyadenylation site. See Materials and Methods for details. $B-K$, Expression of transgene and $p l p / d m-20$ message during embryonic development of plp-sh ble-lacZ mice. Enzymatic $\beta$-gal activity was detected in whole-mount embryos at E8.5 $(B, C)$ and E9.5 $(D)$ and on brain and spinal cord at E12.5 $(F-I)$, E14.5 $(J)$, and E17.5 $(K)$, using either the X-gal or Bluo-gal $(H)$ substrate. Expression of endogenous plp was detected by ISH with a DIG-labeled $p l p$ antisense cRNA on E9.5 sagittal cryosections $(E) . B, C$, At E8.5, $\beta$-gal activity is detected in neural crest cells arising from the mesencephalon and the rostral rhombencephalon $(B)$. Caudally, $\beta$-gal activity is expressed in the notocord facing the unsegmented plate (arrow), as seen on a transversal cryosection counterstained with fuschin $(C) . D, E$, At E9.5, the transgene is first expressed (Figure legend continues) 
In the rhombencephalon and the spinal cord, transgeneexpressing cells appeared at E10.5 in both the basal and alar plate. In the ventral region of the hindbrain, the pattern of $\beta$-gal expression was discontinuous. $\beta$-gal ${ }^{+}$cells were present in rhombomeres 1 and 2 (r1-r2), but rare in rhombomeres 3-5 (r3-r5) (Fig. $1 F-H)$. The absence of expression in the $\mathrm{r} 3-\mathrm{r} 5$ region persisted at E14.5 and E17.5 (Fig. 1J,K). In the caudal hindbrain (r6-r7) and the spinal cord, the $\beta$-gal-expressing cells formed two continuous bilateral longitudinal domains located ventrally and ventrolaterally in the basal plate. $\beta$-gal-expressing cells were also detected in the rhombic lip and in the dorsal alar plate of the spinal cord, forming two columns on either side of the roof plate, from $\mathrm{r} 6$ to the junction between the cervical and thoracic regions (Fig. 1I). Similar to the situation in the brain, on transversal sections of the spinal cord from E14.5 animals there was a continuum of cells expressing the transgene from the lateroventral ventricular layer toward the ventral tract (data not shown).

\section{The transgene is expressed in differentiated oligodendrocytes}

We first examined whether the lac $Z$ transgene was expressed by cells of the oligodendrocyte lineage in the plp-sh ble-lac $Z$ transgenic lines. At E16.5, expression of the pre-oligodendrocyte marker O4 (Sommer and Schachner, 1981; Bansal et al., 1992) by $\beta$-gal ${ }^{+}$cells was observed in the caudal hindbrain and cervical spinal cord. The double-labeled cells were distributed in the marginal zone, mainly within the ventral longitudinal fascicles (Fig. $2 A, B$ ). Similarly, many $\beta$-gal ${ }^{+}$cells, with a typical bipolar morphology, were double-labeled with the anti-NG2 antibody (data not shown), which recognized a proteoglycan specifically expressed by oligodendrocyte progenitors (Levine and Stallcup, 1987). At P1, in the medulla and spinal cord, all of the differentiated oligodendrocytes recognized by the oligodendrocytespecific RIP mAb (Friedman et al., 1989) and localized in the marginal zone of the alar and basal plates were $\beta$-gal ${ }^{+}$(data not shown).

\section{The transgene is not expressed in neuronal cells}

We investigated the possibility that $\beta$-gal ${ }^{+}$cells distributed in the ventricular and subventricular layers of the CNS between E9.5 and E13.5 belonged to the neuronal lineage. The pattern of expression of the transgene was compared with that of Phox-2b, a paired-box type transcription factor that labels neuronal progen- itors and neurons in the midbrain and hindbrain (Pattyn et al., 1997). Although the immunopositive Phox-2b and $\beta$-galexpressing cells were colocalized regionally in the rhombic lip, the caudal hindbrain (r6-r7 region) and the cervical spinal cord, the Phox- $2 \mathrm{~b}^{+}$cells were clearly distinguishable from the $\beta$-gal ${ }^{+}$cells (Fig. $2 C$ ). In addition, on cryosections stained with the Bluo-gal substrate and immunolabeled with the pan-neuron $\mathrm{Hu}$ polyclonal antibody (Szabo et al., 1991), the $\beta$-gal ${ }^{+}$cells were located in the ventricular zone and were clearly negative for $\mathrm{Hu}$. In the subventricular zone, the vast majority of cells were $\beta$-gal ${ }^{+} / \mathrm{Hu}$ negative and $\mathrm{Hu}^{+} / \beta$-gal negative (Fig. $2 D$ ). A similar result was obtained with the pan-neuron marker TuJ1 (Easter et al., 1993) (data not shown). Finally, the pattern of expression obtained by in situ hybridization with a digoxigenin-labeled NeuroD cRNA probe (Lee et al., 1995) on whole-mount X-gal-stained E10.5 and E11.5 embryos was limited to the mantle layer of alar regions of the prosencephalon and mesencephalon, where the transgene was not detected (data not shown). These four convergent observations demonstrate that the transgene is not expressed in neuronal cells.

\section{In culture, transgene expression is restricted to cells of the oligodendroglial lineage}

We then analyzed the phenotype of $\beta$-gal ${ }^{+}$cells in culture. For this purpose, cultures derived from neuroepithelial cells, isolated from E12.5 transgenic embryos, were double-labeled with either $\mathrm{X}$-gal or anti- $\beta$-gal antibodies and markers specific to astrocytes (anti-GFAP) (Bignami et al., 1972), radial glial cells (RC-2 mAb) (Misson et al., 1988), neurons ( $\mathrm{TuJ} 1 \mathrm{mAb}$ ), or oligodendrocytes (O4 mAb). As expected from the in vivo observations, neurons in culture were always $\beta$-gal negative (Fig. 3G,H). In addition, neither radial glial cells (Fig. 3D-F) nor astrocytes (Fig. 3I,J) showed detectable $\beta$-gal enzymatic activity. In contrast, most of the $\beta$-gal ${ }^{+}$cells were ${ }_{4}^{+}$, and some presented the bipolar or poorly branched morphology characteristic of preoligodendrocytes (Fig. $3 A-C$ ). In the $4^{+} / \beta$-gal ${ }^{+}$cells, the X-gal staining was diffusely distributed in the cytoplasm and, in some instances, at the cell membrane. These $\mathrm{O}^{+}{ }^{+}$cells were frequently distributed at the periphery of cores of $\beta$-gal ${ }^{+} / \mathrm{O} 4^{-}$cells in which the $\mathrm{X}$-gal staining appeared as a blue dot. The latter were also labeled with the $\mathrm{A}_{2} \mathrm{~B}_{5}$ antibody, a marker of oligodendrocyte progenitors (data not shown) (Raff, 1989; Rao and MayerProschel, 1997).

\footnotetext{
in the CNS in the caudal hypothalamus $(c H)$, the basal plate of diencephalon $(b p D)$, the dorsal metencephalon $(d M t)$, and the rhombic lip $(R L)$. This pattern of $\beta$-gal expression in the embryonic brain is superimposable on the distribution of $p l p / d m$ - 20 transcripts detected by ISH ( $E$ ). Note, in $D$, that $\beta$-gal expression is maintained in cells derived from the neural crest localized in the mesectoderm of the mandibular branchial arch $(m d)$, the cranial and spinal nerves and ganglia (small arrows), as well as in the nerves and ganglia of the autonomous nervous system (arrowhead). $F-I$, In the CNS of E12.5 embryos from line numbers $1(F), 14(G, I)$, and $34(H)$, the patterns of transgene expression are superimposable. In addition to the rostral pattern observed at E9.5, there is expression in the olfactory bulb $(O b)$, the entopeduncular area (asterisk), the zona limitans intrathalamica $(Z L)$ (limit between the $\mathrm{p} 2-\mathrm{p} 3$ prosomeres), the posterior commissure (arrowhead), and dorsally in the diencephalomesencephalic junction (DMj). In the cervical spinal cord $(S C), \beta$-gal activity is detected both dorsally and ventrally. In the spinal cord, the dorsal territory of expression of the transgene (illustrated on a dorsal view in $I$ ) stops at the cervicothoracic junction. Note the absence of detectable transgene-expressing cells in the mesencephalic basal plate and rhombomeres r3-r5. $J$, $K$, Overview of a mediosagittal section of the brain at E14.5 $(J)$ and E17.5 $(K)$. At E14.5 $(J)$ the diencephalic basal plate is homogeneously $\beta$-gal positive from the mammillary region to the mesencephalic/diencephalic limit. Rostrocaudally, four positive areas are observed in the diencephalic alar plate, corresponding to axonal tracts: the stria medullaris $(S M)$ at the level of the eminentia thalami, the zona limitans intrathalamica $(Z L)$, the retroflexus tract $(R t)$, and the posterior commissure $(P C)$. The cerebellar midline is also positive $(C b)$. At E17.5 $(K) \beta$-gal positive domains in the diencephalic basal plate correspond to the area of the mammillotegmental tract $(M t)$ and the rostral pole of the medial longitudinal fascicle $(M L F)$. Dorsally the limit between $\mathrm{p} 4$ and $\mathrm{p} 3$, the zona limitans $(Z L)$, the posterior commissure $(P C)$, and the cerebellar midline $(\mathrm{Cb})$ are also $\beta$-gal positive. Other positive domains correspond to the optic chiasm $(o c)$ and the optic nerve (on), the anterior dorsal midline of the mesencephalon $(M)$, the epithalamus $(E P)$, the pontine nuclei fibers $(P N)$, and the tegmental metencephalic decussation $(T d)$. $M$, Mesencephalon; $M m$, mammillary region; $N P$, neural plate; $O V$, otic vesicle; $R h$, rhombencephalon; $S$, somite; $T$, telencephalon. Scale bar (shown in $B$ ): $B, 480 \mu \mathrm{m} ; C, 65 \mu \mathrm{m}$; $D, F, G, 600 \mu \mathrm{m} ; E, 200 \mu \mathrm{m} ; H, 700 \mu \mathrm{m} ; I, 800 \mu \mathrm{m} ; J, 500 \mu \mathrm{m}$.
} 

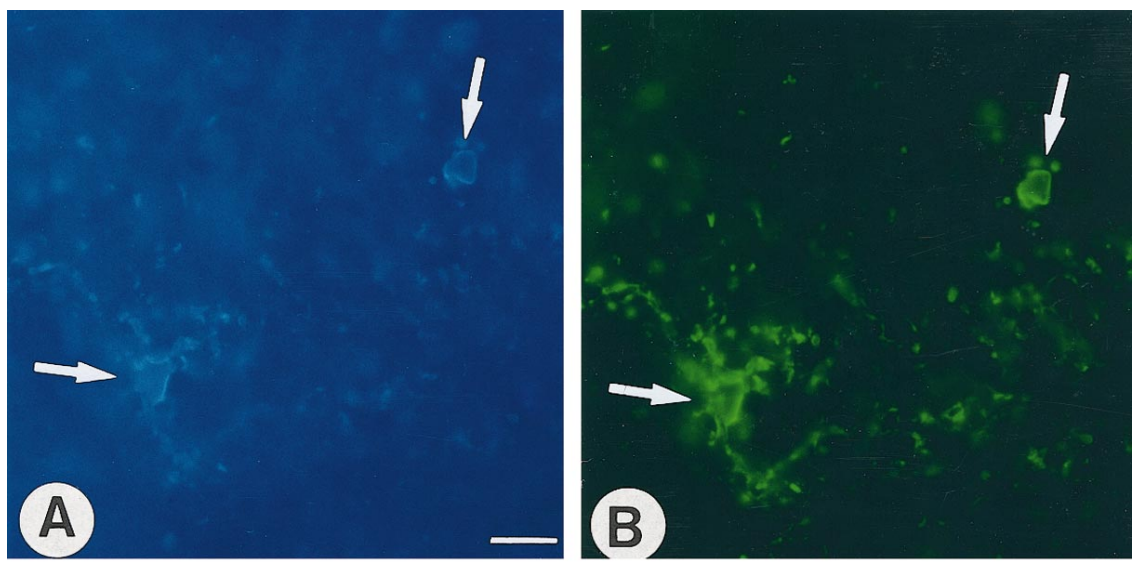

Figure 2. In vivo, the transgene is expressed in cells of the oligodendrocyte lineage but not in neurons. $A, B$, Double-immunofluorescent labeling with anti- $\beta$-gal and $\mathrm{O} 4$ antibody on sagittal cryosections of E16.5 ventral hindbrain. $\beta$-gal ${ }^{+}$cells labeled in blue (AMCA) $(A$, arrows) express the pre-oligodendrocyte marker O4 (fluorescein) (B, arrows). $C, D$, Cryosections double-labeled with Bluo-gal and either $\mathrm{Hu}(C)$ or anti-Phox-2b (D) neuronal-specific antibodies. Coronal section at the level of the diencephalon at E13.5 in $C$, and sagittal section of the rhombencephalon at the level of the rhombic lip at E12.5 in $D$. The $\beta$-gal-expressing cells (dark blue) are located in the ventricular zone, whereas neuronal cells (brown) are mostly observed in the subventricular and intermediate zone and are distinguishable from the $\beta$-gal ${ }^{+}$cells. Scale bar (shown in $A$ ): $A, B, 25 \mu \mathrm{m} ; C, 30 \mu \mathrm{m} ; D$, $35 \mu \mathrm{m}$.
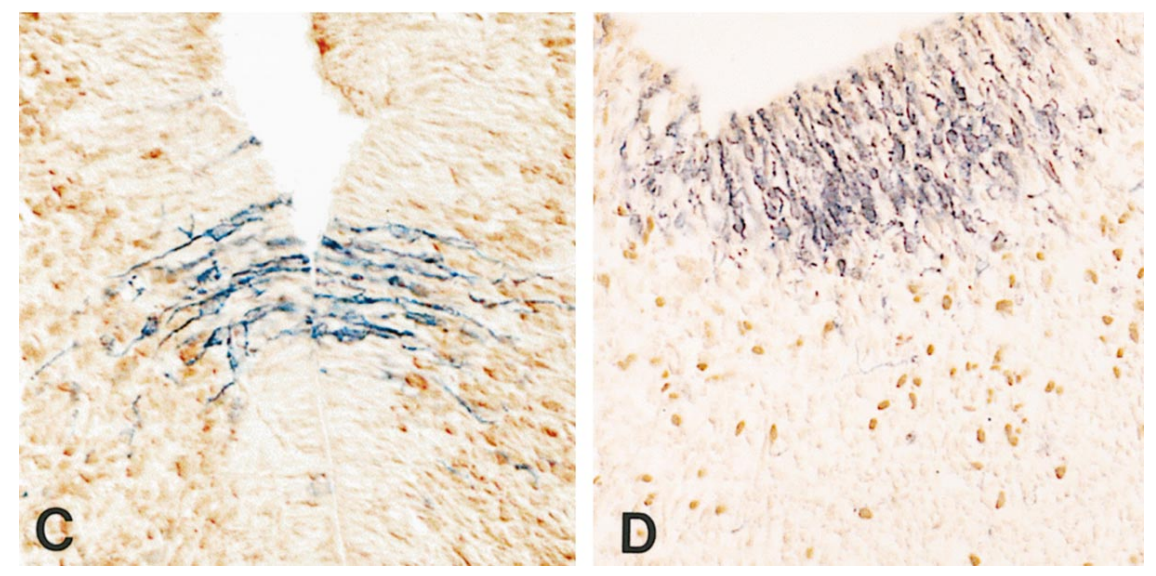

\section{Zeomycin selection of E12.5 plp-sh ble-lacZ neuroepithelial cells in culture}

Expression of the sh ble-lacZ transgene confers to cells both $\beta$-gal enzymatic activity and resistance to the antibiotic zeomycin. Zeomycin, used at a concentration of $75 \mu \mathrm{g} / \mathrm{ml}$, killed $95-100 \%$ of control nontransgenic cultures within 9-10 d, but sh bleexpressing cells survived for several weeks under these conditions. This feature was exploited to analyze the fate of $\mathrm{plp} / \mathrm{dm}$ $20^{+}$precursors that continuously express the transgene. Neuroepithelium of the rostral (ventral diencephalon) and caudal (rhombencephalon and cervical spinal cord) regions of the brain anlage was isolated from plp-sh ble-lacZ embryos at E12.5. The cells were dissociated and cultivated, in either the presence (Fig. $4 D-F$ ) or absence (Fig. $4 A-C$ ) of zeomycin. After 3, 7 (Fig. $4 A-F$ ), and $15 \mathrm{~d}$ in vitro (DIV), the phenotype of the cells was analyzed by evaluating the expression of $\beta$-gal and of the preoligodendrocyte marker recognized by mAb O4. In both the rostral and caudal regions, the abundance of $\beta$-gal ${ }^{+}$cells increased after zeomycin treatment (Fig. $4 G$ ). The percentage of $\beta$-gal ${ }^{+}$cells doubled after 7-8 DIV in the presence of zeomycin compared with untreated cultures. After $10 \mathrm{~d}$ of treatment, most of the $\beta$-gal-negative cells had died, and at $15-16$ DIV, the percentage of $\beta$-gal ${ }^{+}$cells reached $80-90 \%$ of the total cell population. In contrast, in control transgenic cultures, the percentage of transgene-expressing cells from the caudal region was stable over the period analyzed, representing $\sim 20 \%$ of the total population. It increased from 10 to $20 \%$ in cultures derived from the rostral region. Double-labeling with $\mathrm{mAb} \mathrm{O} 4$ showed that after 15 DIV almost all of the $\beta$-gal ${ }^{+}$cells were ${ }^{+}{ }^{+}$preoligodendrocytes, in both zeomycin-treated and untreated cultures. In the treated cultures, $90 \%$ of zeomycin-resistant cells were $\beta$-gal ${ }^{+} /$
$\mathrm{O} 4{ }^{+}$, whereas in control cultures double-labeled cells represented only $15-20 \%$ of the total population (Fig. $4 G$ ). Zeomycin treatment did not alter oligodendrocyte differentiation, because in zeomycin-treated cultures, the percentage of $\mathrm{O}^{+} / \mathrm{X}-\mathrm{gal}^{+}$cells in the $\mathrm{X}-\mathrm{gal}^{+}$population was the same as in control cultures without antibiotic: $20 \%$ at $3-4$ DIV, $50 \%$ at $7-8$ DIV, and $90 \%$ at $15-16$ DIV (Fig. 4G). Even after $15 \mathrm{~d}$ in zeomycin, $10-20 \%$ of the cells did not express the transgene. None of these $\beta$-gal ${ }^{-}$cells were $\mathrm{O}_{4}{ }^{+}$. Some were stained with the $\mathrm{TuJ} 1 \mathrm{mAb}$, but most were either $\mathrm{GFAP}^{+}$or negative for all of these antibodies.

The enrichment in pre-oligodendrocytes after zeomycin treatment of cultures derived from rostral and caudal territories of the brain anlage indicated that, in both regions, cells expressing the transgene gave rise to oligodendrocytes. Because these selection experiments were performed in a culture medium containing PDGF-AA, we asked whether the transgene-selected cells would also develop in the absence of the trophic factor. The zeomycin selection experiment was therefore repeated in the absence of PDGF. When neuroepithelial cells from the rostral region of E12.5 transgenic embryos were cultivated in a zeomycincontaining medium without PDGF (Fig. 4, columns $R z-P$ ), no significant difference in the selection, rate of proliferation, or survival of the selected cells was observed, but their progression along the oligodendroglial differentiation pathway was retarded: after $15 \mathrm{DIV}, 77.2 \pm 4.9 \%$ were $\mathrm{X}-\mathrm{gal}^{+} / \mathrm{O} 4^{+}$in the presence of

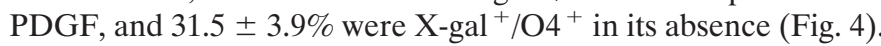

\section{$\beta$-Gal expression defines a distinct origin of oligodendrocytes}

Having established that zeomycin-selected transgene-expressing cells generate oligodendrocytes, we asked whether oligodendro- 

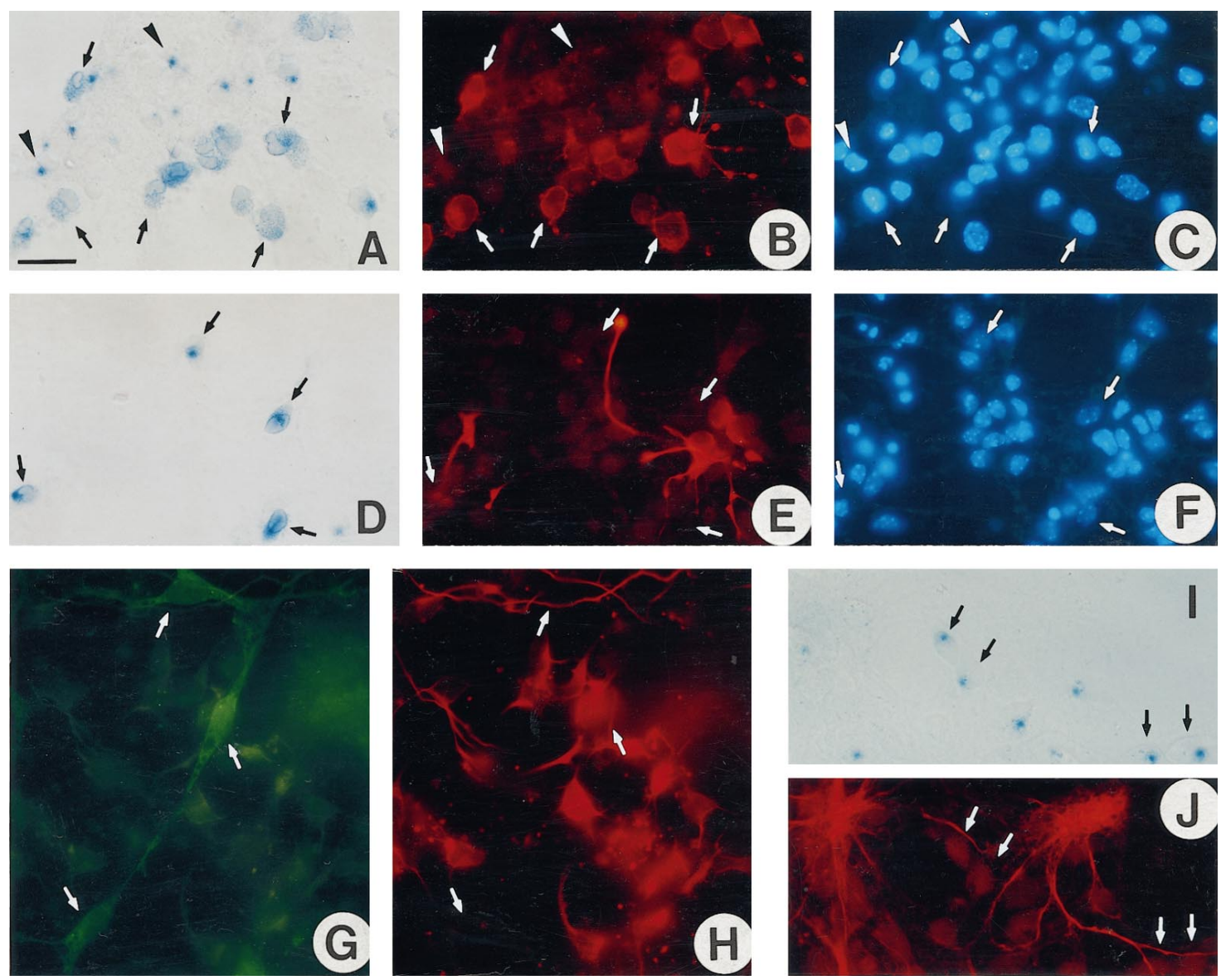

Figure 3. In culture, the transgene is expressed only in cells of the oligodendrocyte lineage. Cultures of caudal neuroepithelium isolated from E12.5 plp-sh ble-lacZ embryos were processed at 3 DIV $(D-F)$ or 8 DIV $(A-C, G-J)$, for $\beta$-gal expression using either X-gal substrate $(A, D, I)$ or anti- $\beta$-gal antiserum $(G)$, then immunolabeled with antibodies specific for pre-oligodendrocytes (O4 in $B)$, radial glial cells $(\mathrm{RC} 2$ in $E)$, neurons (TuJ1 in $H)$, and astrocytes (anti-GFAP in $J$ ). Nuclei were stained with Hoechst reagent $(C, F)$. The same field is shown in $A-C, D-F, G, H$, and $I, J$, respectively. $A-C$, $\mathrm{O}^{+}{ }^{+}$pre-oligodendrocytes $(B)$ are $\beta$-gal ${ }^{+}$with a diff use intracytoplasmic staining $(A)$. Neuroepithelial cells in which the $\mathrm{X}$-gal staining appears as a blue dot (arrowhead) are $\mathrm{O}^{-} . D-F, \mathrm{RC}^{+}{ }^{+}$radial glial cells $(E)$ are $\beta$-gal negative $(D)$. $G, H$, TuJ1 ${ }^{+}$neurons $(H)$ are $\beta$-gal negative $(G)$. $I, J$, GFAP ${ }^{+}$ astrocytes $(J)$ are $\beta$-gal negative $(I)$. Scale bar (shown in $A$ ): $A-F, 70 \mu \mathrm{m} ; G-J, 50 \mu \mathrm{m}$.

glial potential was restricted to CNS domains expressing the $p l p / d m-20$ transcript. For this purpose, neuroepithelial territories, either positive (basal plate of diencephalon, dorsal region around the diencephalomesencephalic sulcus, rhombomeres $r 1-r 2$, dorsal or ventral halves of the cervical spinal cord, and ventral portion of thoracolumbar spinal cord) or negative (telencephalon, mesencephalon, rhombomeres $\mathrm{r} 3-\mathrm{r} 5$, dorsal part of the thoracolumbar spinal cord) for $\beta$-gal expression were carefully dissected at E12.5. After dissociation, cells were cultivated for 7 or $15 \mathrm{~d}$ before being phenotyped as described above.

After 15 DIV, all of the basal territories of the forebrain and midbrain had generated $\mathrm{O}^{+}{ }^{+}$pre-oligodendrocytes (Table 1). However, the proportion of these that were $\mathrm{X}$-gal ${ }^{+}$depended on the territory from which the cells were derived. In cultures from the $\beta$-gal ${ }^{+}$diencephalon, $54 \%$ of the $\mathrm{O}^{+}{ }^{+}$cells were also X-gal ${ }^{+}$, whereas the proportion never exceeded $4-5 \%$ in either telencephalic or mesencephalic cultures. In contrast, in cultures derived from the alar plate around the diencephalomesencephalic sulcus, although no $4^{+}$cells were detected, numerous $\beta$-gal ${ }^{+}$cells were present. Even after 2 weeks in culture, these $\beta$-gal ${ }^{+}$cells remained nestin $^{+}$, a marker of neural multipotent cells, and none were immunostained with any of the specific markers for neurons, radial glial cells, or astrocytes.

In both the dorsal cervical spinal cord, which strongly expressed the transgene, and the $\mathrm{r} 3-\mathrm{r} 5$ region, where $<1 \%$ of the cells expressed the transgene when the cultures were established (Table 2), $\mathrm{O} 4^{+}$cells were observed. In the $\mathrm{r} 3-\mathrm{r} 5$ region, however, the $\beta$-gal ${ }^{+}$cells represented only 4 and $25 \%$ of the $\mathrm{O}^{+}$cells at 7 and 15 DIV, respectively, whereas in all the other caudal regions analyzed, the proportion of $\beta$-gal ${ }^{+}$cells among the $\mathrm{O} 4^{+}$ cells was in the range of $70-90 \%$. No oligodendrocytes developed from the $\beta$-gal-negative dorsal thoracolumbar spinal cord, as already demonstrated in the rat by Wharf et al. (1991).

The kinetics of $\mathrm{O} 4$ expression in the different territories of the brain differed considerably between caudal and rostral cultures. In the hindbrain and spinal cord, $\mathrm{O}^{+}{ }^{+}$cells were already numerous at 7 DIV (Table 2), and some could be detected as early as 3 DIV (Fig. $4 G$ ). In the forebrain, no O4 ${ }^{+}$cells were detected at 7 DIV, but they could be observed at 15 DIV. To time the appearance of pre-oligodendrocytes in the forebrain and midbrain, cultures originating from telencephalon, diencephalon, or mesencephalon were analyzed at 9 and 11 DIV. The first $\mathrm{O}^{+}$cells 
Figure 4. Oligodendroglial enrichment as a function of time after zeomycin treatment of cultures from E12.5 plp-sh ble-lacZ neuroepithelial cells. Cells from caudal $(C$, rhombencephalon and cervical spinal cord) or rostral ( $R$, mesencephalon and ventral diencephalon) territories of the CNS were cultivated in a PDGF-containing medium in the absence $(C, R)$ or presence $(C z, R z)$ of zeomycine $(75 \mu \mathrm{g} / \mathrm{ml})$. In some experiments, cells were cultivated in the presence of zeomycine in a medium without PDGF $(R z-P)$. $\beta$-gal activity was detected with the $\mathrm{X}$-gal substrate. Preoligodendrocytes were detected by immunostaining with $\mathrm{mAb}$ O4. $A-F$, Typical fields of caudal neuroepithelium from E12.5 plp-sh ble-lacZ embryos, cultured in the absence $(A-C)$ or presence $(D-F)$ of zeomycine, and then processed at $8 \mathrm{DIV}$ for both $\beta$-gal $(A, D)$ and $\mathrm{O} 4$ expression $(B, E)$. Nuclei are stained with Hoechst reagent $(C, F)$. The same field is shown in $A-C$ and $D-F$, respectively. In the absence of zeomycine $(A-C), 2$ of 15 cells in the field are $\mathrm{X}-\mathrm{gal}^{+} / \mathrm{O}^{+}$pre-oligodendrocytes with diff use $\mathrm{X}$-gal labeling in their cytoplasm (arrows). Note three other $\mathrm{X}-\mathrm{gal}^{+} / \mathrm{O} 4^{-}$cells, considered to be precursor cells, with $\mathrm{X}$-gal labeling concentrated in one dark-blue spot $(A$, arrowhead). In the presence of zeomycine $(D-$ $F), 10$ of 28 cells in the field are $\mathrm{X}$-gal ${ }^{+} /$ $\mathrm{O}^{+}$pre-oligodendrocytes. Note that almost all of the $\mathrm{X}$-gal ${ }^{+}$cells show diffuse X-gal labeling in the cytoplasm. $G$, The percentage of $\mathrm{X}-\mathrm{gal}^{+}$cells in the cultures is indicated in blue. The percentage of $\mathrm{O}^{+}$cells among the $\mathrm{X}$-gal ${ }^{+}$population appears in red. After 2 weeks of zeomycine treatment, almost $70-90 \%$ of the cells express the transgene in the rostral and caudal territories in culture medium with or without PDGF. Note that in control cultures the proportion of $\mathrm{X}$-gal ${ }^{+}$ cells remains constant. Oligodendrocyte enrichment is similar in rostral and caudal territories, although oligodendrocytes differentiate 1 week later in the rostral territories. Results are the mean $\pm \mathrm{SD}$ of at least three different experiments in duplicate. Scale bar, $70 \mu \mathrm{m}$.
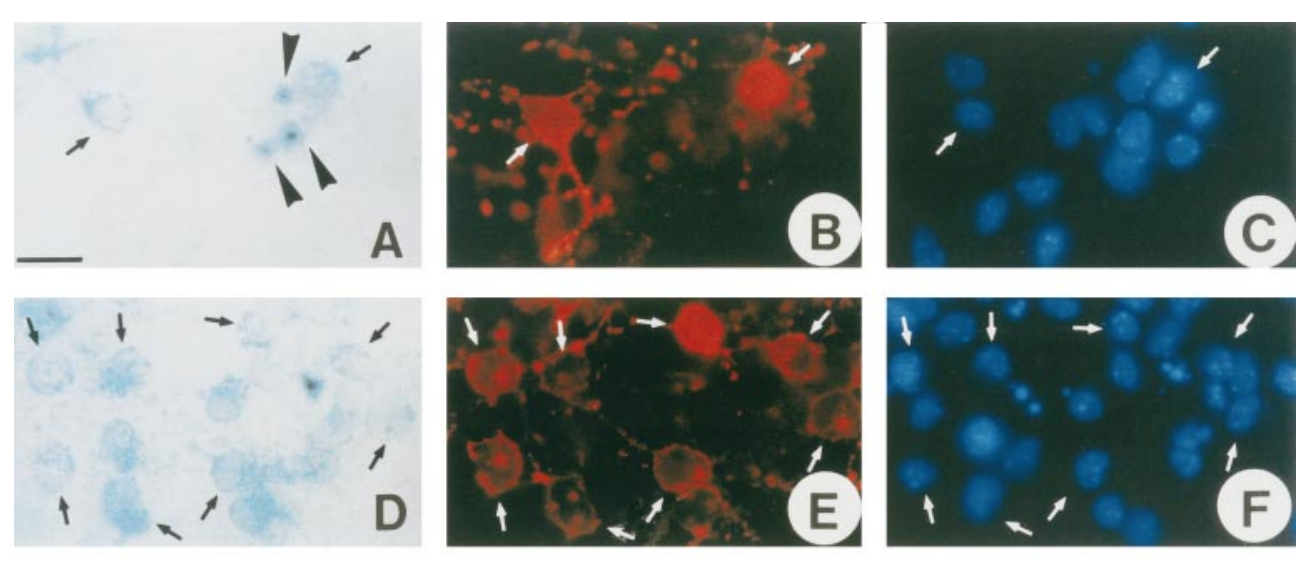

\section{G}

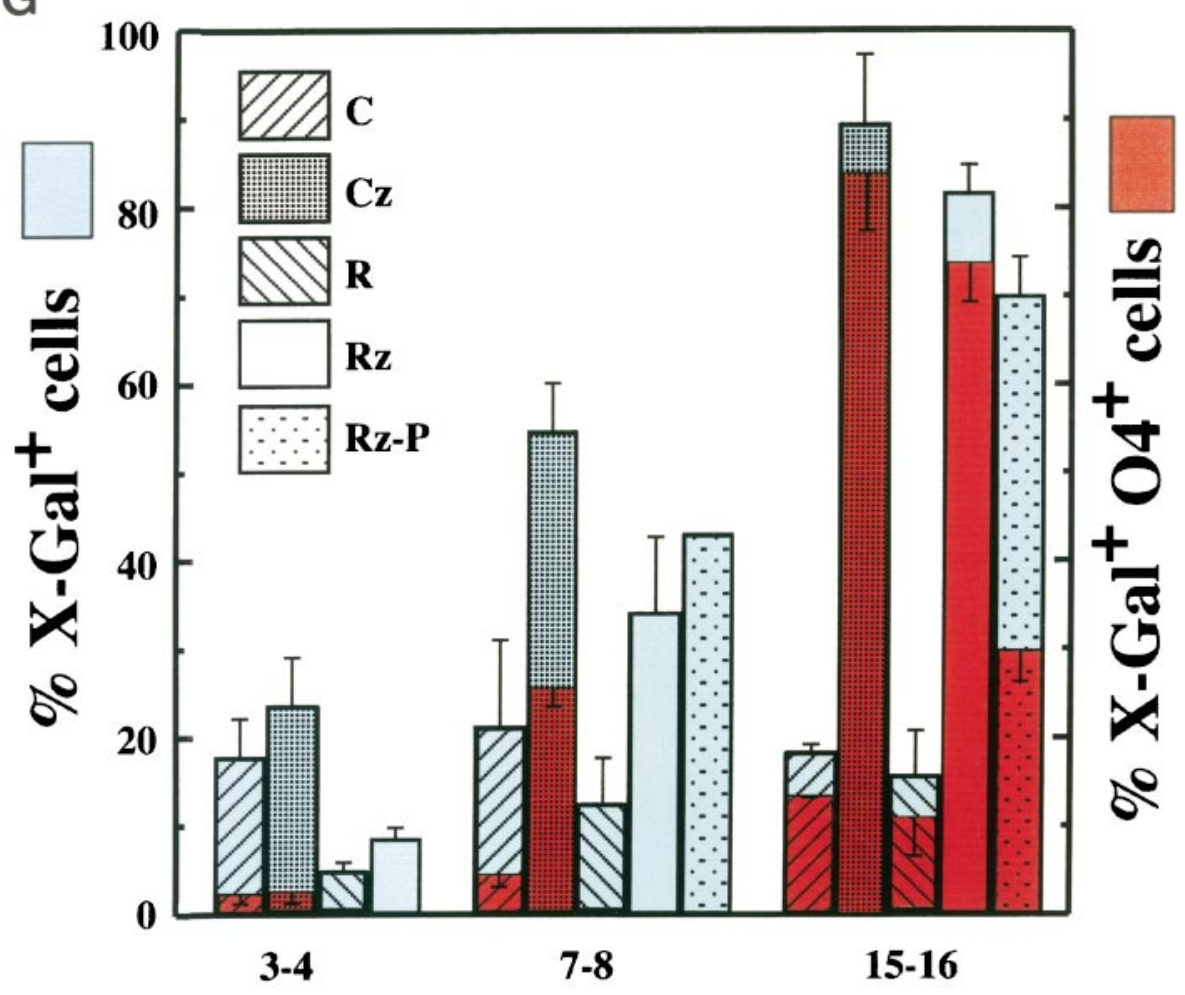

\section{Days in vitro}

were observed at 9 DIV in the telencephalic cultures and at 11 DIV in the diencephalic and mesencephalic cultures.

\section{Comparison of PDGFR $\alpha$ and $p / p / d m-20$ expression patterns in the developing CNS}

Because oligodendrocytes develop from both $\beta$-gal $(p l p)$-negative as well as $\beta$-gal $(p l p)$-positive precursors, we investigated the possibility that the $\beta$-gal-negative oligodendrocyte precursors might express $P D G F R \alpha$, another possible early marker for oligodendrocyte precursors (Pringle and Richardson, 1993).

Serial cryosections from E10.5 wild-type mouse embryos were hybridized in situ with either $p l p / d m-20$ or PDGFR $\alpha$ digoxigeninlabeled cRNA probes. The patterns of expression of $p l p / d m-20$ and PDGFR $\alpha$ was strikingly distinct (Fig. 5A-C). PDGFR $\alpha$ expressing cells were detected in territories such as the ganglionic eminence (Fig. 5A), the dorsal thalamus, and rhombomeres r3-r5, without significant expression of $p l p / d m-20$. In contrast,
$P D G F R \alpha^{+}$cells were scarce in the strongly plp-dm-20-positive basal plate of prosomeres p1-p2 (Fig. 5B), zona limitans intrathalamica, caudal hypothalamus and entopeduncular area, or the dorsal cervical spinal cord $(5 C)$. At E12.5, transgenic embryos were treated for both $\beta$-gal detection and in situ hybridization with a digoxigenin-labeled PDGFR $\alpha$ probe. The two markers were again mutually exclusive (Fig. $5 D, E$ ). Cryosections from E14.5 and E17.5 embryos were treated for double in situ hybridization with digoxigenin- and fluorescein-labeled plp/dm-20 and $P D G F R \alpha$ cRNA probes (Fig. $5 F, G$ ). At these developmental stages, in addition to the ventricular localization, cells expressing one or the other of the transcripts were also distributed in the parenchyma. Only rare, usually multi-process bearing cells located at a distance from the ventricular zone co-expressed both transcripts. Although some double-labeled cells may not be clearly visible (the light $\mathrm{BCIP} / \mathrm{INT}$ reaction product could be 
Table 1. Oligodendroglial differentiation potential of E12.5 prosencephalic territories

\begin{tabular}{|c|c|c|c|c|c|c|c|c|}
\hline \multirow[b]{2}{*}{ DIV } & \multicolumn{2}{|c|}{ Telencephalon } & \multicolumn{2}{|c|}{$\begin{array}{l}\text { Ventral } \\
\text { diencephalon }\end{array}$} & \multicolumn{2}{|c|}{$\begin{array}{l}\text { Dorsal } \\
\text { diencephalic/ } \\
\text { mesencephalic } \\
\text { junction }\end{array}$} & \multicolumn{2}{|c|}{$\begin{array}{l}\text { Ventral + dorsal } \\
\text { mesencephalon }\end{array}$} \\
\hline & 7 & 15 & 7 & 15 & 7 & 15 & 7 & 15 \\
\hline X-gal positive & - & - & + & + & + & + & - & - \\
\hline O4 positive & - & + & - & + & - & - & - & + \\
\hline$\% \mathrm{X}-\mathrm{gal}^{+} / \mathrm{O}^{+}$ & - & 5 & - & 54 & - & - & - & 4 \\
\hline
\end{tabular}

Table 1 shows the capacity of various regions of the prosencephalon to give rise to oligodendrocytes. The analysis was conducted on E12.5 plp-sh ble-lac $Z$ embryos, and the territories examined were chosen on the basis of their expression of the transgene as shown in Fig. $1 F-H$. Dissection and culture conditions were as described in Materials and Methods. After 7 or $15 \mathrm{~d}$ in vitro (DIV), cultures were double-stained with X-gal and $\mathrm{mAb} \mathrm{O} 4$, and scored + or.$- \%$ X-gal ${ }^{+} / \mathrm{O}^{-}{ }^{-}$(bottom line) indicates the percentage of X-gal-positive cells among the $\mathrm{O}^{+}$population. In all the caudal territories, $\mathrm{O}^{+}$cells were already observed at 3-4 DIV, whereas in the rostral regions $\mathrm{O} 4$ was expressed only at $9-11$ DIV.

\begin{tabular}{|c|c|c|c|c|c|c|c|c|c|c|}
\hline \multirow[b]{2}{*}{ DIV } & \multicolumn{2}{|c|}{$\mathrm{R} 1-\mathrm{R} 2$} & \multicolumn{2}{|c|}{ R3-R5 } & \multicolumn{2}{|c|}{$\begin{array}{l}\text { Ventral cervical } \\
\text { spinal cord }\end{array}$} & \multicolumn{2}{|c|}{$\begin{array}{l}\text { Dorsal cervi- } \\
\text { cal spinal cord }\end{array}$} & \multirow{2}{*}{$\begin{array}{l}\begin{array}{l}\text { Ventral lumbar } \\
\text { spinal cord }\end{array} \\
7\end{array}$} & \multirow{2}{*}{$\begin{array}{l}\text { Dorsal lumbar } \\
\text { spinal cord }\end{array}$} \\
\hline & 7 & 15 & 7 & 15 & 7 & 15 & 7 & 15 & & \\
\hline X-gal positive & + & + & \pm & \pm & + & + & + & + & + & - \\
\hline $\mathrm{O} 4$ positive & + & + & + & + & + & + & + & + & + & - \\
\hline$\% \mathrm{X}_{-\mathrm{gal}^{+}} / \mathrm{O}^{+}$ & 65 & 73 & 4 & 25 & 88 & 89 & 96.5 & 80 & 78.5 & - \\
\hline
\end{tabular}

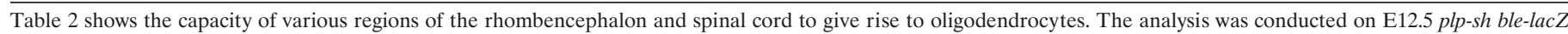

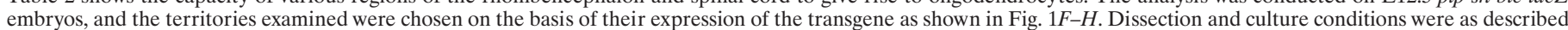

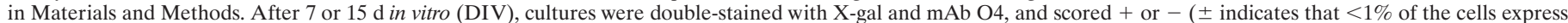

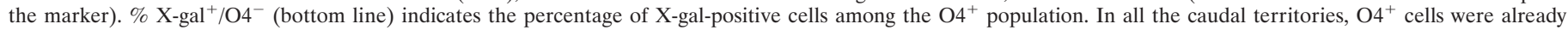
observed at 3-4 DIV, whereas in the rostral regions O4 was expressed only at 9-11 DIV.

obscured in some cells by the dark blue NBT/BCIP product), it appeared that the majority of the labeled cells expressed only one of the two mRNA species. These results support the possibility that $\mathrm{plp} / \mathrm{dm}-20^{+}$and PDGFR $\alpha^{+}$cells are separate populations of precursors and that they do not represent different stages in the same cell lineage.

\section{DISCUSSION}

We have produced transgenic mice carrying both the lacZ reporter and the zeomycin resistance (sh ble) genes driven by the plp promoter and regulatory sequences to test the possibility that plp/dm-20-expressing embryonic neuroepithelial cells can differentiate into oligodendrocytes.

\section{Concordant patterns of expression of $p / p / d m-20$ transcripts and lac $Z$ transgene}

In the three plp-sh ble-lacZ lines examined, the spatiotemporal pattern of expression of the plp/dm-20 transcript (Timsit et al., 1992, 1995; Dickinson et al., 1996; Peyron et al., 1997) is superimposable on the pattern of expression of the lac $Z$ reporter (Fig. 1 ). In the CNS, but not in the PNS where expression of endogenous $p l p / d m-20$ is higher, the number of cells expressing the plp/dm-20 transcripts detectable by in situ hybridization was lower than the number of $\beta$-gal ${ }^{+}$cells. Similarly, we noted that in some territories the $\beta$-gal activity was detectable earlier than the $p l p /$ $d m-20$ transcripts. Differences in the respective thresholds of detection of the $\beta$-gal enzymatic activity and of $p l p / d m-20$ transcripts by in situ hybridization most probably account for these minor discrepancies.

\section{plp/dm-20 as a marker of the oligodendrocyte lineage}

PLP and DM-20 are established markers of both the myelin sheath and myelinating oligodendrocytes (Lees and Brostoff,
1984; Dubois-Dalcq et al., 1986; Monge et al., 1986). Here we show that transcription of plp occurs earlier along the oligodendroglial differentiation pathways. Lubetzki et al. (1991) have already reported the presence of plp/dm-20 mRNA in highly purified oligodendrocyte progenitors, bulk-isolated from newborn rat brain. Similarly, in rat and mouse premyelinated optic nerve (between E18 and P5), at least some of the oligodendrocyte progenitors expressed $\mathrm{plp} / \mathrm{dm}$-20 message and protein (Fanarraga et al., 1996).

\section{Are the $p / p / d m-20$ cells in the germinative neuroepithelium restricted to the oligodendroglial lineage or multipotent precursors?}

Between E9.5 and E12.5, the plp/dm-20 ${ }^{+}$cells are densely packed at the ventricular surface. As expected for a precursor cell, they are proliferative and remain so late into embryonic development, long after the period of neurogenesis. The question remains whether $p l p / d m$-20-expressing cells in the germinative neuroepithelium are precursors of the oligodendrocyte lineage. The dramatic enrichment in pre-oligodendrocytes observed in the $p l p$-sh ble-lac Z zeomycin-treated cultures is demonstrative of $p l p$ promoter activation, and therefore of continuous $\mathrm{plp} / \mathrm{dm}$-20 expression, during the progression along the oligodendroglial lineage from the stage of precursor until their final differentiation and maturation.

Both in vivo and in vitro, the differentiated cells expressing the sh ble-lac $Z$ transgene have an oligodendroglial rather than astroglial or neuronal phenotype, but zeomycin selection does not indicate whether they are restricted or pluripotent precursors. Indeed, after 15-16 d of zeomycin treatment, the cultures derived from E12.5 neuroepithelium still contained $10-20 \%$ of 
Figure 5. In the developing embryonic mouse brain, $P D G F R \alpha$ and $p l p / d m-20$ are expressed in distinct cell populations. Cryosections of wild-type mouse embryo at E10.5 $(A, B), \mathrm{E} 14.5(F)$, and E17.5 $(G)$, or E12.5 plp-sh ble-lacZ embryos $(D, E)$ were treated for ISH with either PDGFR $\alpha(A, D-G)$ or plp-dm-20 DIG- $(B)$ or fluorescein-labeled $(F, G)$ antisense cRNA probes. $A, B$, On coronal sections, $P D G F R \alpha^{+}$cells are seen in the medial ganglionic eminence $(A)$, whereas $p l p-d m-20^{+}$cells are detected in the laterobasal plate of the diencephalon $(b p D)(B)$. In $A$, the strong staining in the bottom right and left corners illustrates the expression of PDGFR $\alpha$ in nonneural tissues. $C$, Drawing of an E10.5 mouse CNS embryo showing the distribution of PDGFR $\alpha^{+}$and plp-dm-20 cells. $D, E$, Sagittal $(D)$ and coronal $(E)$ sections of an E12.5 transgenic embryo treated for histoenzymatic detection of $\beta$-gal activity (X-gal, light blue) and ISH with a PDGFR $\alpha$ cRNA (dark purple) showing expression of the transgene in the zona limitans $(Z L)$ (p2-p3 interprosomeric boundary) $(D, E)$ and the caudal hypothalamus $(D)$, whereas $P D G F R \alpha^{+}$ cells are seen in the medial ganglionic eminence $(M G E$ in $D)$ and the dorsal thalamus ( $d T h$ in $E) . F, G$, Coronal section at the level of the rhombic lip $(F)$ and sagittal section at the level of the medulla $(G)$, labeled by double ISH showing that the PDGFR $\alpha^{+}$cells (small arrows, pink or orange staining) and plp$d m-20^{+}$cells (arrow heads, dark purple) are distinct populations. Scale bar (shown in $A$ ): $A, 180 \mu \mathrm{m} ; B, 190 \mu \mathrm{m}$; $D, 200 \mu \mathrm{m} ; E, 150 \mu \mathrm{m} ; F, 30 \mu \mathrm{m} ; G$, $120 \mu \mathrm{m}$.
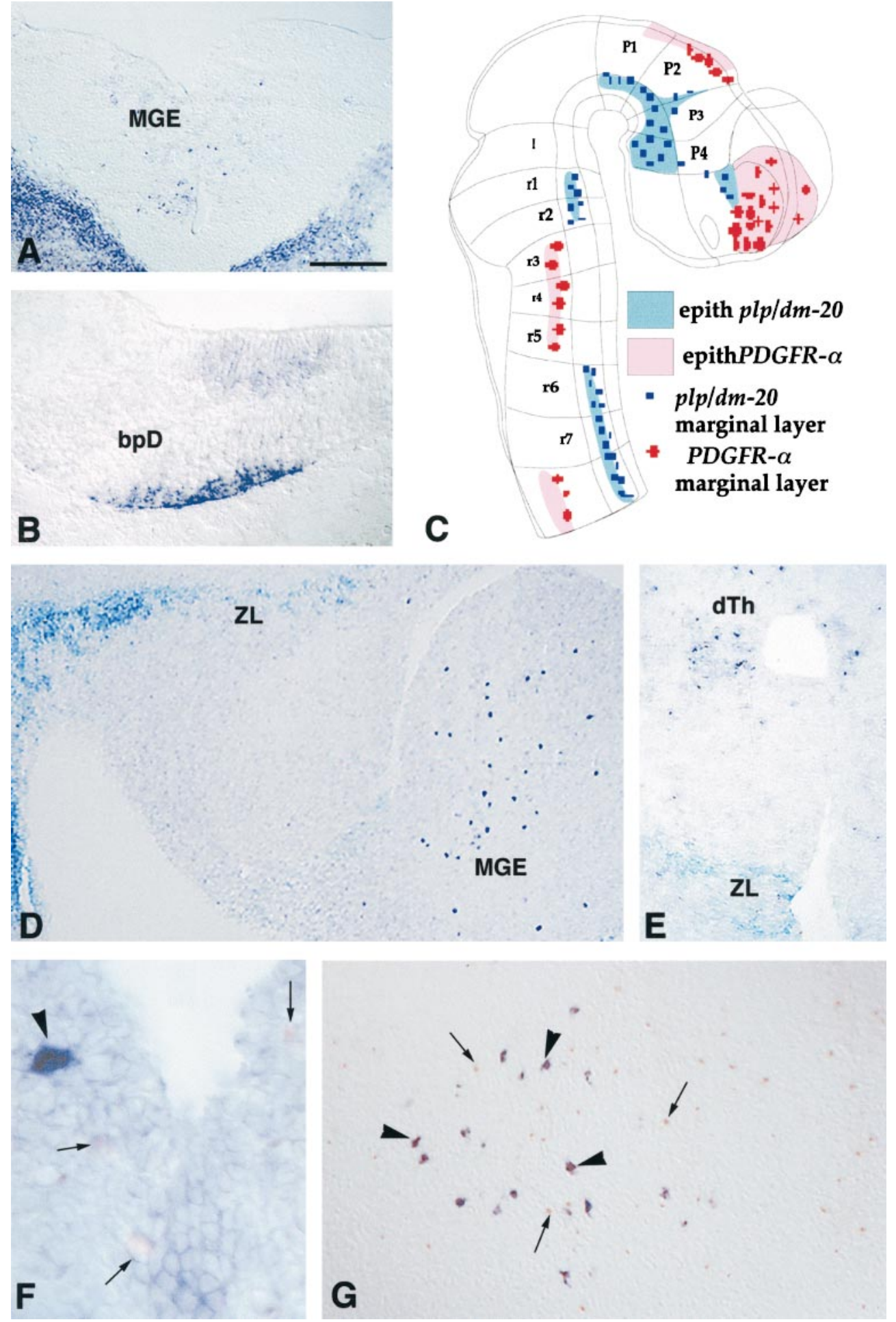

$\beta$-gal-negative astrocytes and neurons. It is unlikely that these cells or their precursors were present at the time of seeding but were resistant to the antibiotic. More probably, these $\beta$-galnegative cells have been generated, in vitro, from already present $\beta$-gal ${ }^{+}$multipotent precursors. Generation of neurons and oligodendrocytes from a common precursor cell in culture has been reported by Williams and Price (1995). Retroviral labeling of the subventricular zone of the postnatal rat forebrain in vivo showed that these cells can form clones containing oligodendrocytes and astrocytes and even neurons (Levison and Goldman, 1993). More recently, it has been proposed that the capability of a stem-like founder cell to generate neurons, astrocytes, or oligodendrocytes is dependent on the FGF2 concentration (Qian et al., 1997). The plp/dm-20-expressing cells of the germinative neuroepithelium therefore would not be restricted to an oligodendroglial fate. If these multipotent precursors adopt a neuronal or astroglial fate, $p l p / d m-20$ expression will be turned off. Maintenance of expression of plp/dm-20 will indicate, however, that these cells are engaged in an oligodendroglial differentiation pathway. 


\section{Multiple origin of oligodendrocytes}

\section{Along the rostrocaudal axis}

The $p l p / d m$-20-expressing cells in the embryonic neuroepithelium can generate oligodendrocytes, as shown by the zeomycin selection experiments. However, oligodendrocytes can form in brain territories that do not express the transgene, such as the mesencephalon or the rhombomeres $\mathrm{r} 3-\mathrm{r} 5$, from a precursor of unknown phenotype. In the spinal cord, oligodendrocyte precursors, originating in a very restricted region of the ventricular zone, might be characterized by the expression of PDGFR $\alpha$ (Pringle et al., 1992; Pringle and Richardson, 1993). In developing rat brain, $\mathrm{PDGFR} \alpha^{+}$cells colocalize with the oligodendrocyte progenitor marker NG2 proteoglycan (Nishiyama et al., 1996). Furthermore, PDGFR $\alpha$-expressing cells, selected by immunopanning, differentiate into ${ }^{+}{ }^{+}$pre-oligodendrocytes (Hall et al., 1996). Whether PDGFR $\alpha$ expression is indicative of oligodendroglial specification in the brain is less clear, however, because it has been shown that the vast majority of PDGFR $\alpha^{+}$cells during late embryonic development are neurons (Nait Oumesmar et al., 1997).

Here we show that the patterns of expression of PDGFR $\alpha$ and $p l p / d m-20$ are strikingly different in both the germinative and mantle layers of embryonic mouse brain, strongly suggesting that the two populations of $P D G F R \alpha^{+}$and $p l p / d m-20^{+}$precursor cells are clonally distinct. In vitro, most of the $\mathrm{O}^{+}$cells developing from the $P D G F R \alpha^{+} / p l p / d m-20^{-}$r3-r5 rhombomeres were $\beta$-gal negative and therefore may derive from oligodendrocyte precursors (or migrating progenitors) expressing the $P D G F R \alpha$, but not $p l p / d m-20$. In cultures derived from the ventral spinal cord, where the two populations coexist, $>70 \%$ of the $\mathrm{O} 4{ }^{+}$cells were $\beta$-gal ${ }^{+}$. This result seems in contrast to the data from Hall et al. (1996) suggesting that a majority of spinal cord oligodendrocytes are derived from PDGFR $\alpha^{+}$precursors. However, taking into account that in the spinal cord oligodendroglial differentiation occurs much earlier, a possible explanation for this discrepancy is that $\beta$-gal expression at 15 DIV is indicative of maturing oligodendrocytes, regardless of their origin.

It remains possible, however, that the $p l p / d m-20^{+}$and PDGFR $\alpha^{+}$cells represent different stages in the same lineage. This is unlikely for two reasons. First, between E10.5 and E17.5, even in CNS regions like the ventral spinal cord where there is territorial co-expression of the two markers, there is no coexpression at the cellular level in the ventricular neuroepithelium. The rare double-labeled cells are located outside the ventricular layer and correspond, most likely, to predifferentiated or newly differentiated oligodendrocytes. Second, PDGF-AA has been described as a potent proliferation and survival factor for the oligodendrocyte progenitors (Noble et al., 1988; Raff et al., 1988; Richardson et al., 1988). We did not observe any significant modification of the proliferation or survival of zeomycin-selected cells grown in the absence of PDGF, although it has to be noted that the experiments by Noble et al. (1988) and Raff et al. (1988) were performed in the absence of serum, whereas our experimental conditions include $1 \%$ fetal calf serum. However, in the absence of PDGF, or after withdrawal of PDGF from the medium, oligodendrocyte progenitors rapidly differentiate into postmitotic oligodendrocytes (Noble et al., 1988; Raff et al., 1988). We observed, on the contrary, a delayed differentiation of the zeomycin-selected cells maintained in the absence of PDGF. The effect of PDGF on the differentiation of $p l p / d m-20$ cells into oligodendrocytes may be mediated by $\operatorname{PDGFR} \alpha$ expressed at levels below the sensitivity of our in situ hybridization technique. If this is the case, activation of PDGFR $\alpha$ on the $p l p / d m-20$ cells would have the opposite effect to what has been described previously in the oligodendroglial lineage. Alternatively, withdrawal of PDGF from the culture medium of the $p l p / d m-20^{+}$cells, which inhibits their differentiation, could be mediated by a different molecular mechanism not involving $\operatorname{PDGFR} \alpha$.

Two distinct oligodendroglial lineages appear to develop in the CNS, therefore, one of which is defined by the expression of plp/dm-20 at the nonrestricted precursor stage and subsequently along the oligodendroglial differentiation pathway; the other is defined by the expression of PDGFR $\alpha$.

\section{Along the ventrodorsal axis}

The concept that the oligodendroglial lineage originates ventrally was based on the observation that dorsal regions of the thoracic and lumbar spinal cord, unlike the corresponding ventral portions, do not acquire the capacity for oligodendrogenesis until late during development (Wharf et al., 1991; Trousse et al., 1995). This does not appear to be the case for the dorsal cervical spinal cord, which expresses plp/dm-20 transcript and is capable of oligodendrogenesis. These observations corroborate the study of Cameron-Curry and LeDouarin (1995) based on isotopic and isochronic exchanges of the E2 spinal cord between quail and chick embryos, which demonstrated that oligodendrocytes were generated in vivo from both dorsal and ventral halves of the neural tube. In a recent study, however, Pringle et al. (1998) reported that dorsal grafts produced astrocytes but not oligodendrocytes, and that in spinal cord cultures only ventral cells generated oligodendrocytes, whereas both ventral and dorsal cells generated astrocytes. It is of note that in the latter study both in vivo and in vitro experiments were performed at the thoracic level but not at the cervical level.

\section{Significance of a multiple origin for oligodendrocytes}

Del Rio-Hortega (1928) and Penfield (1932) have suggested that oligodendrocytes are heterogeneous on the basis of morphological criteria (size of the cell body, number of myelinated internodes, diameter of myelinated axons). These authors distinguished four sub-groups of oligodendrocytes. More recently, other subpopulations have been described on the basis of on biochemical criteria: expression of carbonic anhydrase II, or P2 protein, or a member of the collapsin response mediator protein family (Trapp et al., 1983; Butt et al., 1995; Honnorat et al., 1998). It has also been observed that subsets of oligodendrocytes are not equally resistant to toxic agents such as hexachlorophene or cuprizone (Cammer et al., 1975; Ludwin, 1978; Komoly et al., 1987). For the present, however, it is impossible to correlate this morphological and biochemical heterogeneity with a specific embryonic origin, dorsal or ventral, or $p l p / d m-20^{+}$or PDGFR $\alpha^{+}$.

\section{REFERENCES}

Bansal R, Steffanson K, Pfeiffer SE (1992) POA, a developmental antigen expressed by A007/O4-positive oligodendrocyte progenitors prior to the appearance of sulfatide and galactocerebroside. J Neurochem 58:2221-2229.

Bignami A, Eng LF, Dahl D, Uyeda CT (1972) Localization of the glial fibrillary acidic protein in astrocytes by immunofluorescence. Brain Res 43:429-431.

Bottenstein JE, Sato GH (1979) Growth of rat neuroblastoma cell line in serum-free supplemented medium. Proc Natl Acad Sci USA 76:514-517.

Butt AM, Ibrahim M, Ruge FM, Berry M (1995) Biochemical subtypes of oligodendrocyte in the anterior medullary velum of the rat as revealed by the monoclonal antibody Rip. Glia 14:185-197. 
Cameron-Curry P, LeDouarin N (1995) Oligodendrocyte precursors originate from both the dorsal and the ventral parts of the spinal cord. Neuron 15:1299-1310.

Cammer W, Rose AL, Norton, WT (1975) Biochemical and pathological studies of myelin in hexachlorophene intoxication. Brain Res 27:547-559.

Del Rio-Hortega P (1928) Tercera aportacion al conocimiento morfologica e interpretacion functional de la oligodendroglia. Mem Real Soc Expan Hist Nat 14:5-122.

Dickinson PJ, Fanarraga ML, Griffiths IR, Barrie JM, Kyriakides E, Montague P (1996) Oligodendrocyte progenitors in the embryonic spinal cord express DM-20. Neuropathol Appl Neurobiol 22:188-198.

Drocourt D, Calmels T, Reynes JP, Baron M, Tiraby G (1990) Cassettes of the Streptoalloteichus hindustanus ble gene for transformation of lower and higher eukaryotes to phleomycin resistance. Nucleic Acids Res 18:4009.

Dubois-Dalcq M, Behar T, Hudson LD, Lazzarini RA (1986) Emergence of three myelin proteins in oligodendrocytes cultured without neurons. J Cell Biol 102:384-392.

Easter Jr SS, Ross LS, Frankfurter A (1993) Initial tract formation in the mouse brain. J Neurosci 13:285-299.

Eisenbarth GS, Walsh FS, Niremberg M (1979) Monoclonal antibody to a plasma membrane antigen of neurons. Proc Natl Acad Sci USA 76:4913-4917.

Fanarraga ML, Dickinson PJ, Sommer I, Montague P, Kyriakides E, Griffiths IR (1996) Evidence that some oligodendrocyte progenitors in the developing optic pathway express the plp gene. Glia 18:282-292.

Friedman B, Hockfield S, Black JA, Woodruff KA, Waxman SG (1989) In situ demonstration of mature oligodendrocytes and their processes: an immunocytochemical study with a new monoclonal antibody, RIP. Glia 2:380-390.

Gatignol A, Durand H, Tiraby G (1988) Bleomycin resistance conferred by a drug-binding protein. FEBS Lett 230:171-175.

Hall A, Giese NA, Richardson WD (1996) Spinal cord oligodendrocytes develop from ventrally derived progenitor cells that express PDGF alpha-receptors. Development 122:4085-4094.

Hardy RJ, Friedrich Jr JL (1996) Oligodendrocyte progenitors are generated throughout the embryonic mouse brain, but differentiate in restricted foci. Development 122:2059-2069.

Henrique D, Adam J, Myat A, Chitnis A, Lewis J, Ish-Horowicz D (1995) Expression of a Delta homologue in prospective neurons in the chick. Nature 375:787-790.

Hogan B, Constantini F, Lacy E (1986) Manipulating the mouse embryo: a laboratory manual. Cold Spring Harbor, NY: Cold Spring Harbor Laboratory.

Honnorat J, Aguera M, Zalc B, Goujet C, Deweerdt L, Quach T, Aunis D, Antoine JC, Belin MF (1998) POP 66, a paraneoplastic encephalomyelitis related antigen homologous to UNC 33 protein, is specifically expressed by a subpopulation of oligodendrocytes in the adult brain. J Neuropathol Exp Neurol 57:311-322.

Ikenaka K, Kagawa T, Mikoshiba K (1992) Selective expression of DM20 , an alternatively spliced myelin proteolipid gene product, in developing nervous system of the mouse. J Neurochem 58:2248-2253.

Kanfer J, Parenty M, Goujet-Zalc C, Monge M, Bernier L, Campagnoni AT, Dautigny A, Zalc B (1989) Developmental expression of myelin proteolipid, basic protein, and 2', 3'-cyclic nucleotide $3^{\prime}$ phosphodiesterase transcripts in different rat brain regions. J Mol Neurosci 1:39-46.

Komoly S, Jeyasingham MD, Pratt OE, Lantos PL (1987) Decrease in oligodendrocyte carbonic anhydrase activity preceding myelin degeneration in cuprizone induced demyelination. J Neurol Sci 79:141-148.

Lee JE, Hollenberg SM, Snider L, Turner DL, Lipnick N, Weintraud H (1995) Conversion of Xenopus ectoderm into neurons by NeuroD, a basic helix-loop-helix protein. Science 268:836-844.

Lees MB, Brostoff SW (1984) Proteins of myelin. In: Myelin (Morell P, ed), pp 197-224. New York: Plenum.

Levi G, Topilko P, Schneider-Maunoury S, Lasagna M, Mantero S, Cancedda R, Charnay P (1996) Defective bone formation in krox-20 mutant mice. Development 122:113-120.

Levine JM, Stallcup WB (1987) Plasticity of developing cerebellar cells in vitro studied with antibodies against the NG2 antigen. J Neurosci 7:2721-2731.

Levison SW, Goldman JE (1993) Both oligodendrocytes and astrocytes develop from progenitors in the subventricular zone of postnatal forebrain. Neuron 10:201-212.

Lubetzki C, Goujet-Zalc C, Gansmuller A, Monge M, Brillat A, Zalc B
(1991) Morphological, biochemical and functional characterization of bulk isolated glial progenitor cells. J Neurochem 56:671-680.

Ludwin SK (1978) Central nervous system demyelination and remyelination in the mouse: an ultrastructural study of cuprizone toxicity. Lab Invest 3:597-612.

Miller R (1996) Oligodendrocytes origin. Trends Neurosci 19:92-96.

Misson JP, Edwards LA, Yamamoto M, Caviness Jr VS (1988) Identification of radial glial cells within the developing murine central nervous system. Studies based upon a new immunohistochemical marker. Dev Brain Res 44:95-108.

Monge M, Kadiisky D, Jacques C, Zalc B (1986) Oligodendroglial expression and deposition of four major myelin constituents in the myelin sheath during development. Dev Neurosci 8:222-235.

Myat A, Henrique D, Ish-Horowicz D, Lewis J (1996) A chick homologue of Serrate, and its relationship with Notch and Delta homologues during central neurogenesis. Dev Biol 174:233-247.

Nait Oumesmar B, Vignais L, Baron-Van Evercooren A (1997) Developmental expression of platelet-derived growth factor $\alpha$-receptor in neurons and glial cells of the mouse CNS. J Neurosci 17:125-139.

Nishiyama A, Lin XH, Giese N, Heldin CH, Stallcup WB (1996) Colocalisation of NG2 proteoglycan and PDGF alpha-receptor on $\mathrm{O} 2 \mathrm{~A}$ progenitor cells in the developing rat brain. J Neurosci Res 43:299-314.

Noble M, Murray K, Stroobant P, Waterfield MD, Riddle P (1988) Platelet-derived growth factor promotes division and motility and inhibits premature differentiation of the oligodendrocyte/type-2 astrocyte progenitor cell. Nature 333:560-562.

Noll E, Miller RH (1993) Oligodendrocyte precursors originate at the ventral ventricular zone dorsal to the ventral midline region in the embryonic rat spinal cord. Development 118:563-573.

Ono K, Yasui Y, Rutishauser U, Miller RH (1997) Focal ventricular origin and migration of oligodendrocyte precursors into the chick optic nerve. Neuron 19:283-292.

Pattyn A, Morin X, Cremer H, Goridis C, Brunet J-F (1997) Expression and interactions of the two closely related homeobox genes Phox2a and Phox 2b during neurogenesis. Development 124:4065-4075.

Penfield W (1932) Neuroglia: normal and pathological. In: Cytology and cellular pathology of the nervous system, Vol 2, pp 437-443. New York: Hoeber.

Peyron F, Timsit S, Thomas J-L, Kagawa T, Ikenaka K, Zalc B (1997) In situ expression of PLP/DM-20, MBP, and CNP during embryonic and postnatal development of the jimpy mutant and of transgenic mice overexpressing PLP. J Neurosci Res 50:190-201.

Pringle NP, Richardson WD (1993) A singularity of PDGF alphareceptor expression in the dorso-ventral axis of the neural tube may define the origin of the oligodendrocyte lineage. Development 117:525-533.

Pringle NP, Mudhar HS, Collarini EJ, Richardson WD (1992) PDGF receptors in the rat CNS: during late neurogenesis, PDGF alphareceptor expression appears to be restricted to glial cells of the oligodendrocyte lineage. Development 115:535-551.

Pringle NP, Guthrie S, Lumsden A, Richardson WD (1998) Dorsal spinal cord neuroepithelium generates astrocytes but not oligodendrocytes. Neuron 20:883-893.

Qian X, Davis AA, Goderie S, Temple S (1997) FGF2 concentration regulates the generation of neurons and glia from multipotent cortical stem cells. Neuron 18:81-93.

Raff MC (1989) Glial cell diversification in the rat optic nerve. Science 243:1450-1455.

Raff MC, Lillien LE, Richardson WD, Burne JF, Noble MD (1988) Platelet-derived growth factor from astrocytes drives the clock that times oligodendrocyte development in culture. Nature 333:562-565.

Rao M, Mayer-Proschel M (1997) Glial restricted progenitors are derived from multipotent neuroepithelial stem cells. Dev Biol 188:48-63.

Richardson WD, Pringle N, Mosley MJ, Westermark B, Dubois-Dalcq M (1988) A role for platelet-derived growth factor in normal gliogenesis in the central nervous system. Cell 53:309-319.

Rubenstein JLR, Martinez S, Shimamura K, Puelles L (1994) The embryonic vertebrate forebrain: the prosomeric model. Science 266:578-580.

Small RK, Riddle P, Noble M (1987) Evidence for migration of oligodendrocyte-type-2 astrocyte progenitor cells into the developing rat optic nerve. Nature 328:155-157.

Sommer I, Schachner M (1981) Monoclonal antibodies (O1 to O4) to oligodendrocyte cell surfaces: an immunocytological study in the central nervous system. Dev Biol 83:311-327. 
Strähle U, Blader P, Adam J, Ingham P (1994) A simple and efficient procedure for non-isotopic in situ hybridization to sectioned material. Trends Genet 10:75-76.

Szabo A, Dalmau J, Manley G, Rosenfeld M, Wong E, Henson J, Posner JB, Furneaux HM (1991) HuD, a paraneoplastic encephalomyelitis antigen, contains RNA-binding domains and is homologous to Elav and Sex-lethal. Cell 67:325-333.

Timsit SG, Bally-Cuif L, Colman D, Zalc B (1992) DM20 messenger RNA is expressed during the embryonic development of the nervous system of the mouse. J Neurochem 58:1172-1175.

Timsit S, Martinez S, Allinquant B, Peyron F, Puelles L, Zalc B (1995) Oligodendrocytes originate in a restricted zone of the embryonic ventral neural tube defined by DM-20 mRNA expression. J Neurosci 15:1012-1024.

Trapp BD, Itoyama Y, MacIntosh TD, Quarles RH (1983) P2 protein in oligodendrocytes and myelin of the rabbit central nervous system. J Neurochem 40:47-54.

Trousse F, Giess SC, Soula C, Ghandour S, Duprat AM, Cochard P (1995) Notocord and floor plate stimulate oligodendrocyte differenti- ation in cultures of the chick dorsal neural tube. J Neurosci Res 41:552-560.

Warrington AE, Pfeiffer SE (1992) Proliferation and differentiation of $\mathrm{O}_{4}{ }^{+}$oligodendrocytes in postnatal rat cerebellum: analysis in unfixed tissue slices using anti-glycolipid antibodies. J Neurosci Res 33:338-353.

Wharf BC, Fok-Seang J, Miller RH (1991) Evidence for the ventral origin of oligodendrocytes precursors in the rat spinal cord. J Neurosci 11:2477-2488.

Wight PA, Duchala CS, Readhead C, Macklin WB (1993) A myelin proteolipid protein-lacZ fusion protein is developmentally regulated and targeted to the myelin membrane in transgenic mice. J Cell Biol 123:443-454.

Williams B, Price J (1995) Evidence for multiple precursor cell types in the embryonic cerebral cortex. Neuron 14:1181-1188.

Yu W-P, Collarini EJ, Pringle NP, Richardson WD (1994) Embryonic expression of myelin genes: evidence for a focal source of oligodendrocytes precursors in the ventricular zone of the neural tube. Neuron 12:1353-1362. 